\title{
MULTI YEAR AEROSOL CHARACTERIZATIONIN THE TROPICAL ANDES AND IN ADJACENT AMAZONIA USING AERONET MEASUREMENTS
}

\author{
Daniel Pérez-Ramírez ${ }^{\mathrm{a}, \mathrm{b}}$, Marcos Andrade-Flores ${ }^{\mathrm{c}, \mathrm{d}}$, Thomas F. Eck ${ }^{\mathrm{e}, \mathrm{f}}$, Ariel F. \\ Stein $^{\text {g }}$, Norman T. O'Neill ${ }^{\mathrm{h}}$, Hassan Lyamani ${ }^{\mathrm{a}, \mathrm{b}}$, Santiago Gassó ${ }^{\mathrm{i}, \mathrm{j}}$, David N. \\ Whiteman $^{\mathrm{k}}$, Igor Veselovskii, ${ }^{1, \mathrm{~m}}$, Fernando Velarde ${ }^{\mathrm{c}}$ and Alados-Arboledas, L. ${ }^{\mathrm{a}, \mathrm{b}}$
a Applied Physics Department, University of Granada, 18071,Granada, Spain
${ }^{\mathrm{b}}$ Andalusian Institute for Earth System Research (IISTA), Av.Mediterráneo s/n, 18006, Granada, Spain

\begin{abstract}
${ }^{c}$ LaboratoryforAtmosphericPhysics, Universidad Mayor de San Andrés, La Paz, Bolivia.
${ }^{\mathrm{d}}$ Department of Atmospheric and Oceanic Sciences, University of Maryland, College Park, Maryland, United States
\end{abstract}

${ }^{\mathrm{e}}$ Goddard Earth Sciences Technology and Research, University Space Research Association (GESTAR/USRA), 21040, Columbia, Maryland, United States

\section{${ }^{\mathrm{f}}$ Biospheric Sciences Laboratory, NASA Goddard Space Flight Center, 20771, Greenbelt,} Maryland, United States.

${ }^{g}$ NOAA Air Resources Laboratory, 5830 University Research Court, 20740, College Park, Maryland, United States

${ }^{\mathrm{h}}$ Centre d'Applications et de Recherches en Telédetection, Université de Sherbrooke, Sherbrooke, Canada

${ }^{\mathrm{i}}$ Morgan State University, Maryland, United States

${ }^{\mathrm{j}}$ Climate and Radiation Laboratory, NASA Goddard Space Flight Center, 20771, Greenbelt, Maryland, United States.

${ }^{k}$ Mesoscale Atmospheric Processes Laboratory, NASA Goddard Space Flight Center, 20771, Greenbelt, Maryland, United States.

${ }^{1}$ Joint Center for Earth Systems Technology, University of Maryland Baltimore County, Baltimore, Maryland, United States.

${ }^{\mathrm{m}}$ Physics Instrumentation Center of General Physics Institute, Troitsk, Moscow, Russia

Correspondence to: Daniel Perez-Ramirez; E-mail: dperez@ugr.es; 
ABSTRACT

This work focuses on the analysis of columnar aerosol properties in the complex 38 geophysical tropical region of South America within $10-20^{\circ}$ South and $50-70^{\circ}$ West. The region 39 is quite varied and encompasses a significant part of Amazonia (lowlands) as well as high 40 mountains in the Andes (highlands, 4000 $\mathrm{m}$ a.s.l.). Several AERONET stations were included to 41 study the aerosol optical characteristics of the lowlands (Rio Branco, Ji Parana and Cuiaba in 42 Brazil and Santa Cruz in Bolivia) and the highlands (La Paz, Bolivia) during the 2000-2014 43 period. Biomass-burning is by far the most important source of aerosol in the lowlands, 44 particularly during the dry season (August-October). Multi-annual variability was investigated 45 and showed very strong burning activity in 2005, 2006, 2007 and 2010. This resulted in smoke 46 characterized by correspondingly strong, above-average AODs (aerosol optical depths) and 47 homogeneous single scattering albedo (SSA) across all the stations ( 0.93). For other years, 48 however, SSA differences arise between the northern stations (Rio Branco and Ji Parana) with 49 SSAs of $\sim 0.95$ and the southern stations (Cuiaba and Santa Cruz) with lower SSAs of $\sim 0.85$. 50 Such differences are explained by the different types of vegetation burned in the two different 51 regions. In the highlands, however, the transport of biomass burning smoke is found to be 52 sporadic in nature. This sporadicity results in highly variable indicators of aerosol load and type 53 (Angstrom exponent and fine mode fraction) with moderately significant increases in both. 54 Regional dust and local pollution are the background aerosol in this highland region, whose 55 elevation places it close to the free troposphere. Transported smoke particles were generally 56 found to be more optical absorbing than in the lowlands: the hypothesis to explain this is the 57 significantly higher amount of water vapor in Amazonia relative to the high mountain areas. The 58 air-mass transport to La Paz was investigated using the HYSPLIT air-concentration five-days 
59 back trajectories. Two different patterns were clearly differentiated: westerly winds from the

60 Pacific that clean the atmosphere and easterly winds favoring the transport of particles from

61 Amazonia.

62

63 1.- Introduction

High mountain areas are very sensitive to climate change as they host many glaciers and

65 are also involved in many cloud formation processes (e.g. Wonsick et al., 2014; Lüthi et al.,

66 2015). Particularly, high mountains in tropical areas are the host of glaciers and snow at such

67 latitudes, irrigating many rivers and thus are essential for the water supply of local population.

68 Changes in glacial and snow covers are indicators of climate change (e.g. Xu et al., 2016). The

69 Andes in South America is the largest mountain chain in the world covering a latitude range

70 from $-55^{\circ} \mathrm{S}$ to $5^{\circ} \mathrm{N}$ and with many peaks above $5000 \mathrm{~m}$ a.s.l. The Andes mountain chain is part

71 of many countries and is a natural barrier between the bulk of the South American mainland and

72 the Pacific Ocean. It also represents a fundamental constraint on the eastern meteorology given

73 the predominance of easterly trade winds from the Atlantic Ocean. These trade winds create the

74 conditions for the South American Low Level Jet (SALLJ) that runs parallel to the mountains

75 (Ulke et al., 2011). The SALLJ exhibits an annual cycle that peaks during austral summer and is

76 the major air-mass transport mechanism in South America. Despite its low altitude (around 1500

77 m a.s.l.), it enhances moisture availability for convection in the Andes Mountains (Nogués-

78 Paegle and Mo, 1997).In other regions containing large mountain chains such as the Himalaya in

79 Asia or the Alps in Europe many studies have been done concerning trace gases (e.g.

80 Schwikowski et al., 1999; Maione et al., 2011), aerosols (e.g. Gautman et al., 2011; Zieger et al., 
81 2012) and cloud formation (e.g. Bonasoni et al., 2010). In the Andes, however, due to the lack of 82 appropriate measurements, these topics have not been studied well.

The Amazon Basin is a major source of anthropogenic-driven biomass-burning emissions

84 (e.g. Mishra et al., 2015), accounting for approximately 15\% of total global biomass-burning emissions (van der Werfet al., 2010).Depending on the vegetation burned, fires inject reactive gases, greenhouses gases (e.g. as carbon dioxide $\left(\mathrm{CO}_{2}\right)$ and methane $\left.(\mathrm{CH} 4)\right)$ and particles into 87 the atmosphere (Andreae and Merlet, 2001; Bowman et al., 2009; Remy et al., 2014).Biomass88 burning emissions are also a major source of organic (14-77 $\mathrm{Tg} / \mathrm{yr}$ ) and black carbon particles 89 (1.8-11 Tg/yr)(e.g. Bond et al., 2013). Aerosol smoke particles that are the result of biomass90 burning directly affect the Earth-Atmosphere radiative budget by scattering and absorbing solar 91 radiation (e.g. Jacobson, 2014) and also indirectly by acting as cloud condensation nuclei (CCN) 92 and ice nuclei (IC) and thereby changing the distribution and properties of clouds (e.g. Koren et 93 al., 2008). Biomass-burning can be the cause of serious public health issues such as extreme 94 particulate matter (PM) concentrations caused by fires in the island of Borneo and Sumatra (Eck 95 et al., 2016). Smoke from wildfires has also been associated with both increased mortality (Vedal and Dutton, 2006) and morbidity (Bowman and Johnston, 2005), and may cause 250,000

97 (73,000-435,000) premature mortalities/yr, with $>90 \%$ being associated with PM (Jacobson, 98 2014).

In Amazonia the smoke emissions caused by agricultural burning of residues (e.g. Uriarte 100 et al., 2009) and by deforestation along the borders of Amazon forests, known as the arc of 101 deforestation (e.g. Morton et al., 2008; van Marle et al., 2016). The burned areas are commonly 102 found in Brazil, Peru, Colombia, Bolivia, Paraguay and northern Argentina. Atmospheric 103 transport patterns lead to spatial distributions of smoke that can be very different from the 
104 distribution of the actual fire sources (e.g. Freitas et al., 2005). This, in turn, has differing 105 impacts on different environments and populations. As an example, many studies have been 106 carried out over Brazilian areas, including modeling transport efforts (e.g. Matichuk et al., 2008; 107 Longo et al., 2010) and the impact of smoke over both rural areas and highly populated cities 108 (e.g. Reid et al., 1998,1999; Kotchenruther et al., 1998). Also, intensive field campaigns such as 109 GOAMAZON (http://campaign.arm.gov/goamazon2014/) have been staged to advance the 110 understanding of absorption and aging properties of smoke, of greenhouse gases and of smoke 111 transport patterns. However, due to the enormous areas burned and the population differences as 112 well as different agricultural traditions and agricultural development between Brazil and its 113 neighbors, the study of biomass burning in the rest of South America needs to be the focus of 114 more investigations.

The main objective of this work is to analyze the smoke particle patterns in the Bolivian 116 Andes and surrounding areas. To that end, we focus on the long-term ground-based 117 measurements of the AERONET network acquired at the high mountain site in the city of La Paz 118 (3340 $\mathrm{m}$ a.s.1) and at nearby lowland sites in Brazil and Bolivia.We usedthe HYSPLIT model 119 (Stein et al., 2015) to interpret the origin of the air masses influencing the study region. Biomass120 burning smoke studies using AERONET data have been successfully carried out in Brazil (e.g. 121 Schafer et al., 2008), Africa (e.g. Eck et al., 2003, 2013: Queface et al., 2011) and in Alaska (e.g. 122 Eck et al., 2009) as well as for cases of long-range transport of biomass burning smoke in North 123 America (e.g. Colarco et al., 2003; Veselovskii et al., 2015), Europe (e.g. Alados-Arboledas et 124 al., 2011) and Asia (e.g. Noh et al., 2009). AERONET data on biomass-burning smoke have also 125 been used to improve and validate satellite retrievals (e.g. Sayer et al., 2014). 
This work is structured as follows: Section II describes the experimental region and methodology. The results are in Section III and concluding remarks in section IV.

\section{2.- Experimental Region and Methodology}

The South American study zone of interest is in the tropical region within $10-20^{\circ}$ South and $50-70^{\circ}$ West. The area includes three different geophysical regions: The Amazon (lowlands) is characterized by tropical conditions, the high mountain regions by mountains above $6000 \mathrm{~m}$ a.s.l. that also include flat areas known as the 'Altiplano' (highlands $~ 4000 \mathrm{~m}$ a.s.l.) and by a transition between the two (foothills). Figure 1 shows a map of the area, including the AERONET stations whose data were used in this study and an example of an elevation profile from the Pacific Ocean to Amazonia crossing the La Paz region. The wet season occurs during the period from December to March, and the dry season is particularly intense in the period from June to September. The most important geo-atmospheric factor is the strong altitude gradient between the lowlands and highlands, with its attendant large differences in water vapor content and relative humidity. The city of La Paz, Bolivia (16.36 ${ }^{\circ}$ South, 68.06 ${ }^{\circ}$ West, $3439 \mathrm{~m}$ a.s.1.), which is located in a valley surrounded by mountains of up to $5500 \mathrm{~m}$ a.s.l is an important focus of this study. The metropolitan area includes the Andean Altiplano with a total population of around 1.7 million inhabitants. The lowlands to the north and east include the stations of Rio

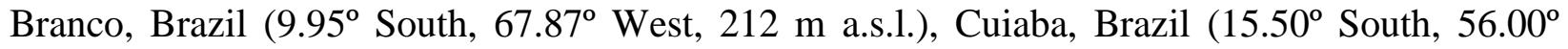
West, $250 \mathrm{~m}$ a.s.1.) and Ji-Parana, Brazil (10.85 ${ }^{\circ}$ South, $61.80^{\circ}$ West, $100 \mathrm{~m}$ a.s.1.) These stations are close to small-medium sized cities with populations in the range of $120,000-600,000$ inhabitants. The station in the Bolivian city of Santa Cruz de la Sierra (17.08 ${ }^{\circ}$ South, $63.17^{\circ}$ West, $442 \mathrm{~m}$ a.s.l.) with a total population of 2 million was also included in our study. 
149 main sources of local anthropogenic aerosol over the study region.
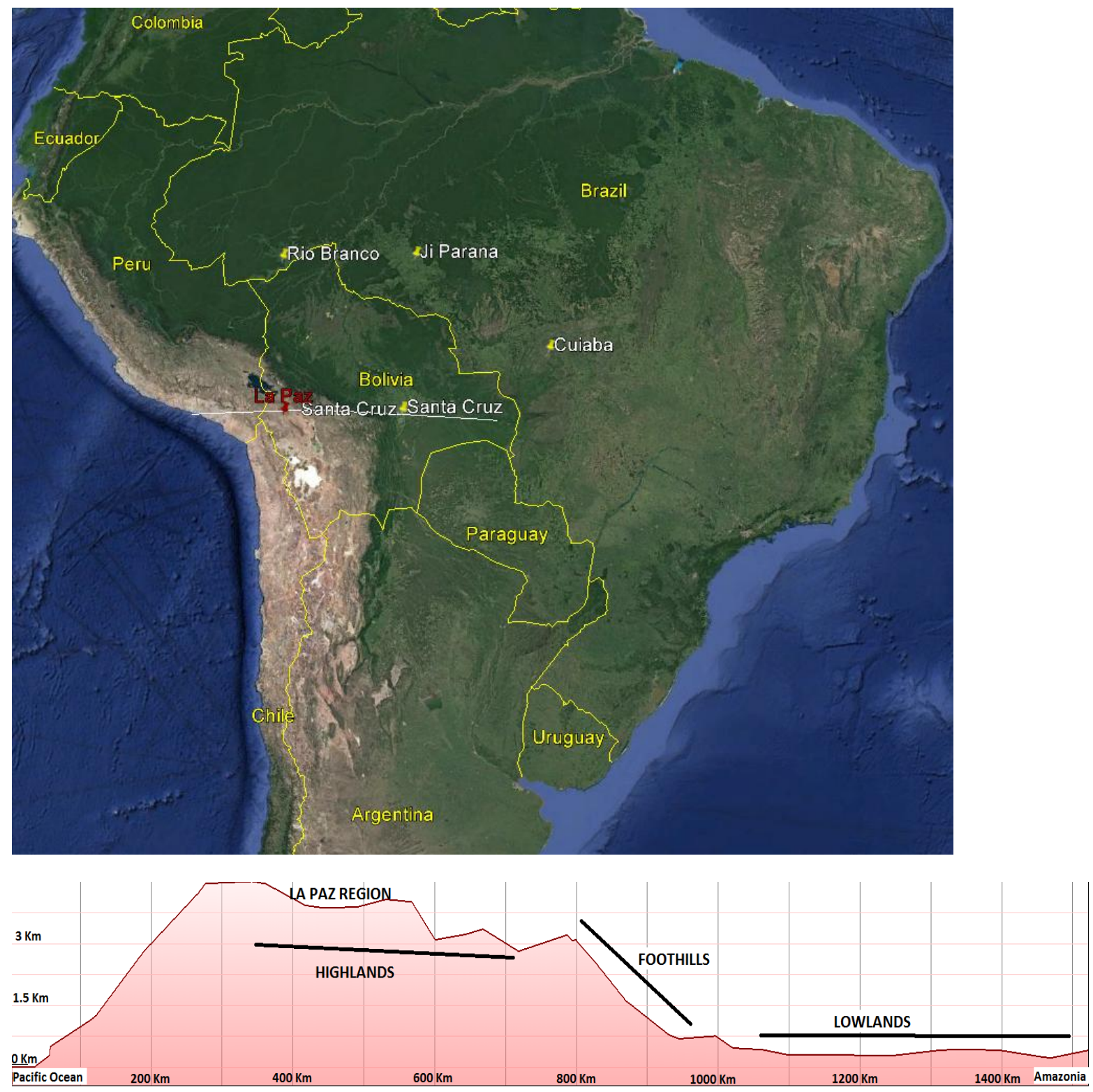

152 Figure 1: Study region including the AERONET stations used. Horizontal line in the map represents the region of 153 the elevation profile.

Column-integrated characterization of atmospheric aerosol was examined using knownCIMEL CE-318-4 sun photometer. This device measures direct sun signals at 340, 380, 
$157440,500,675,870$, and $1020 \mathrm{~nm}$ which are transformed into aerosol optical depths (AODs).

158 Details of AERONET sun photometers including calibration, error analysis and aerosol optical

159 properties retrievals are in Holben et al., (1998), Eck et al.,(1999) and in Smirnov et al., (2000).

160 All the data used in this study are cloud-screened and quality assured (Level 2.0).

Within the solar spectrum, the Angström exponent is a good indicator of the predominant

162 size of atmospheric particles (i.e. Dubovik et al., 2002): $\alpha>1.5$ implies the predominance of

163 fine mode (submicron) aerosols while $\alpha<0.5$ implies the predominance of coarse mode

164 (supermicron) aerosols. However, for a more accurate characterization of the relative influence

165 of fine and coarse mode particles an interpretation based solely on very high or very low values

166 of $\alpha$ is not straightforward. We accordingly used the Spectral Deconvolution Algorithm (SDA)

167 product incorporated into AERONET standardized processing (O’Neill et al., 2001a,b; 2003), to

168 study fine mode $\mathrm{AOD}\left(\mathrm{AOD}_{\text {fine }}\right)$, coarse mode $\mathrm{AOD}\left(\mathrm{AOD}_{\text {coarse }}\right)$, and fine mode fraction

$169\left(\eta=\mathrm{AOD}_{\text {fine }} / \mathrm{AOD}\right)$ at a reference wavelength of $500 \mathrm{~nm}$.

In terms of aerosol microphysical properties, the operational AERONET algorithm

171 (Dubovik and King, 2000; Dubovik et al., 2000) uses sky radiances and direct sun measurements

172 as inputs and provides retrieved aerosol size distribution as well as intensive properties such as

173 aerosol refractive index, single scattering albedo (SSA) and asymmetry factor (g) (across four

174 spectral bands at 440, 675, 870, $1020 \mathrm{~nm}$ ). However, the AERONET algorithm has specific and

175 often difficult to satisfy sky condition requirements (Holben et al., 2006) in that skies must be

176 completely clear and large scattering angles (typically larger than $50^{\circ}$ ). These limitations imply

177 that refractive index retrievals are only reliable for AOD $>0.4$, although not for the retrieval of

178 size distribution (Holben et al., 2006). It accordingly provides low temporal resolution results

179 (generally a maximum of approximately 8 inversions per day are possible). Nevertheless, 
180

181

182

retrievals that uses sky radiance measurements are the only that are able to provide retrieved values of aerosol refractive index, single scattering albedo and phase function with appropriate accuracy (Dubovik et al., 2006).

To complement AERONET retrieved aerosol microphysical properties, we compute additional retrievals using the Linear Estimation technique (Veselovskii et al., 2012, 2013), that uses AERONET spectral AODs measurements as input to yield high frequency estimates of aerosol microphysical parameters during the whole day. The parameters retrieved using the LE technique are the effective radius $\left(\mathrm{r}_{\mathrm{eff}}\right)$ and the volume concentration $(\mathrm{V})$. The other retrievals we ran were based on the method proposed by O`Neill et al., (2005, 2008a), which, itself, is based on the spectral curvature of the fine mode Angstrom slope and its spectral derivative, derived from the SDA. This algorithm is used to estimate the fine mode effective radius $\left(\mathrm{r}_{\mathrm{fine}}\right)$.

The inversions by LE are constrained in the maximum radius allowed in the inversion due to the range of AODs used in the inversion (380 - $1020 \mathrm{~nm}$ ), being improved the retrieval accuracy. Measurements of $\alpha(440-870)$ are used for the selection of the maximum radius in the inversion, being of $2 \mu \mathrm{m}$ for fine mode predominance and of $10 \mu \mathrm{m}$ for the rest of cases. Also, simulations revealed that LE retrievals have an accuracy below $20 \%$ for $\mathrm{r}_{\text {fine }}>0.12 \mu \mathrm{m}$, while the accuracy degrades for lower $\mathrm{r}_{\text {fine }}$ due to the lack of sensitivity of the inversion range to these tiny particles. Posterior comparisons versus AERONET retrievals showed differences of up to $10 \%$ for fine mode predominance and $20 \%$ for coarse mode predominance. The largest uncertainties were found for mixtures of both modes with differences up to $30 \%$. Because the use of LE retrievals is for supporting AERONET inversions, corrections functions are applied which reduced the differences between the two retrieval schemes to generally less than $10 \%$. We remark here that AERONET uncertainties are similar to these ranges being (Dubovik et al., 
203 2000). More details about the use of Linear Estimation retrievals are in Perez-Ramirez et al.,

204 (2015). On the other hand, for the retrievals of $r_{\text {fine }}$ using O'Neill et al., (2005, 2008a)

205 methodology, comparisons versus AERONET retrievals for the limited data set of O'Neill et al.,

2062005 and confirmed by more recently unpublished AERONET-wide comparisons show average

207 differences $\sim 10 \%$ for $\eta$ values $>\sim 0.5$.

208 The HYSPLIT model (Stein et al., 2015), developed by the NOAA Air Resources

209 Laboratory, and accessible on-line at http://www.ready.noaa.gov/HYSPLIT.php is used to

210 compute air parcel backward-trajectories and from them assess dispersion of aerosols. The

211 meteorological data used to run the model were from 6-hourly GDAS (Global Data Assimilation

212 http://www.emc.ncep.noaa.gov/gmb/gdas/) output at $1^{\circ}$ degree horizontal resolution. The total

213 trajectory time was set to 120 hours.

\section{3.- Results}

\section{3.1. Aerosol Optical Properties}

Figure 2 shows the temporal evolution of daily means of $A O D, \mathrm{AOD}_{\text {fine }}$ and $\mathrm{AOD}_{\text {coarse }}$ for

217 the AERONET stations, whose data were employed in our study (with a zoomed insert of the 218 temporal plot of the highlands station of La Paz). The reference wavelength is $500 \mathrm{~nm}$. Table 1

219 presents a statistical summary of the parameters in Figure 2, particularly mean values, standard 220 deviations (STD), medians, maxima and minima.

221 Maxima of $\mathrm{AOD}, \mathrm{AOD}_{\text {fine }}$ and $\mathrm{AOD}_{\text {coarse }}$ occur during the biomass-burning season from

222 August to October. The intensity of the biomass-burning season varies from year to year as 223 evidenced, for example, by the different maximum values of Figure 2. These intense biomass224 burning seasons have also been reported in the literature based on satellite observations (e.g. 
225 Torres et al., 2010). During the biomass-burning season, increases in $\mathrm{AOD}_{\text {fine }}$ and $\mathrm{AOD}_{\text {coarse }}$ are

226 observed when compared with other seasons. But the increase of $\mathrm{AOD}_{\text {fine }}$ is very large compared

227 to that of $\mathrm{AOD}_{\text {coarse, }}$ indicating a large predominance of fine particles (by about an order of

228 magnitude).

229

230

231

232

233

234

235

236

237

238

239

240

241

242

243

244

245

246

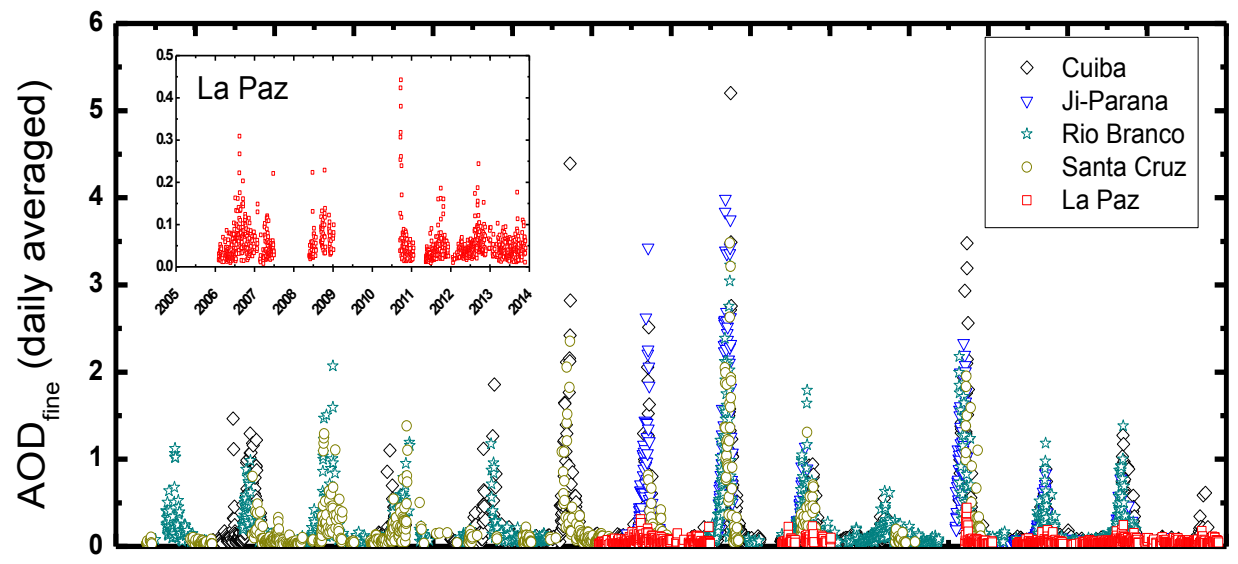

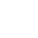

(2)

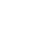

4

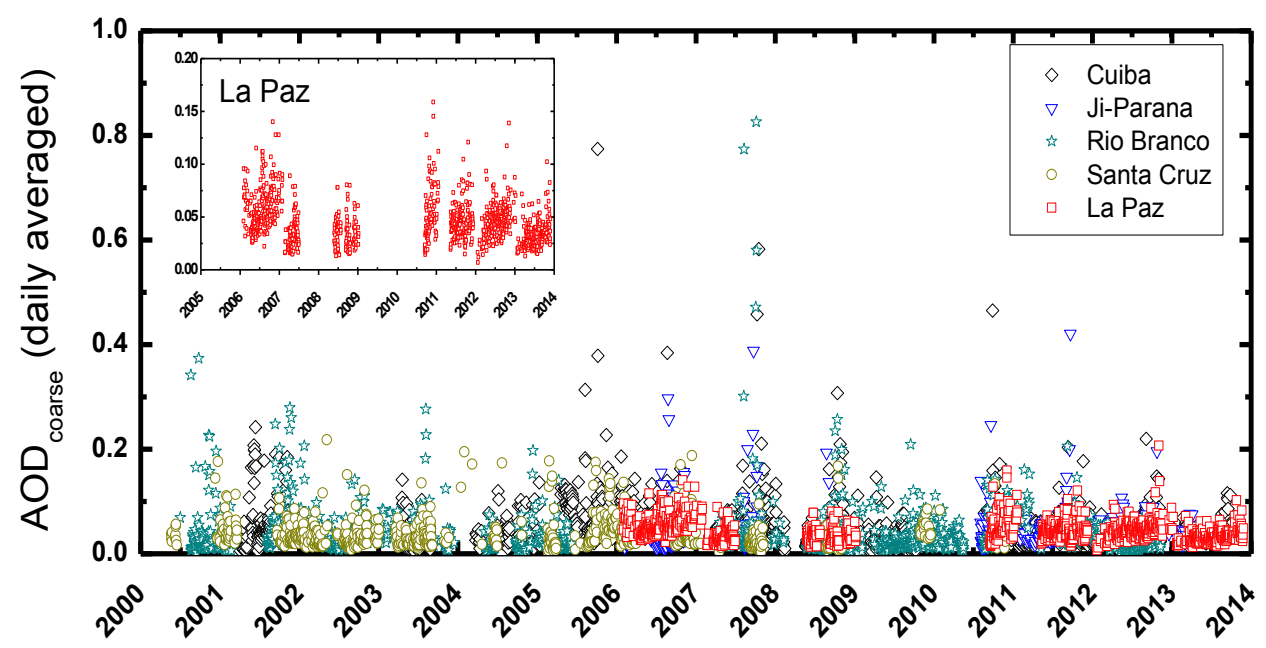

248

Figure 2: Temporal evolution of daily averaged AOD, including these of the fine and coarse mode. Reference wavelength is $500 \mathrm{~nm}$. 


\begin{tabular}{|c|c|c|c|c|c|c|c|c|c|c|c|}
\hline & & AOD & Alpha & $\mathbf{A O D}_{\text {fine }}$ & AOD $_{\text {coarse }}$ & Eta & AOD & Alpha & $A O D_{\text {fine }}$ & AOD $_{\text {coarse }}$ & Eta \\
\hline & & \multicolumn{5}{|c|}{ Biomas-Burning Season } & \multicolumn{5}{|c|}{ No Biomass-Burning Season } \\
\hline \multirow{5}{*}{ Cuiaba } & Mean & 0.55 & 1.56 & 0.48 & 0.06 & 0.82 & 0.13 & 1.15 & 0.08 & 0.04 & 0.64 \\
\hline & STD & 0.61 & 0.30 & 0.55 & 0.06 & 0.14 & 0.09 & 0.32 & 0.08 & 0.03 & 0.14 \\
\hline & Median & 0.35 & 1.63 & 0.29 & 0.05 & 0.85 & 0.11 & 1.15 & 0.07 & 0.04 & 0.64 \\
\hline & Max. & 6.31 & 2.12 & 5.20 & 0.77 & 0.99 & 0.21 & 2.15 & 0.19 & 0.24 & 0.99 \\
\hline & Min. & 0.07 & 1.41 & 0.03 & 0.00 & 0.24 & 0.03 & 0.95 & 0.01 & 0.00 & 0.54 \\
\hline \multirow{5}{*}{ Ji Parana } & Mean & 0.89 & 1.71 & 0.80 & 0.05 & 0.89 & 0.13 & 1.15 & 0.06 & 0.04 & 0.58 \\
\hline & STD & 0.79 & 0.25 & 0.79 & 0.05 & 0.12 & 0.09 & 0.29 & 0.04 & 0.02 & 0.11 \\
\hline & Median & 0.50 & 1.75 & 0.50 & 0.04 & 0.93 & 0.11 & 1.14 & 0.05 & 0.04 & 0.57 \\
\hline & Max. & 4.36 & 2.15 & 3.99 & 0.42 & 0.99 & 0.24 & 1.97 & 0.20 & 0.16 & 0.89 \\
\hline & Min. & 0.07 & 1.55 & 0.04 & 0.01 & 0.54 & 0.03 & 0.95 & 0.01 & 0.01 & 0.20 \\
\hline \multirow{5}{*}{$\begin{array}{c}\text { Rio } \\
\text { Branco }\end{array}$} & Mean & 0.52 & 1.67 & 0.47 & 0.04 & 0.89 & 0.11 & 0.84 & 0.09 & 0.04 & 0.72 \\
\hline & STD & 0.46 & 0.29 & 0.45 & 0.07 & 0.12 & 0.08 & 0.31 & 0.06 & 0.03 & 0.15 \\
\hline & Median & 0.36 & 1.74 & 0.31 & 0.02 & 0.93 & 0.09 & 0.82 & 0.08 & 0.02 & 0.75 \\
\hline & Max. & 3.53 & 2.40 & 3.22 & 0.92 & 0.99 & 0.19 & 1.92 & 0.15 & 0.18 & 0.98 \\
\hline & Min. & 0.06 & 1.54 & 0.04 & 0.01 & 0.22 & 0.02 & 0.62 & 0.02 & 0.00 & 0.20 \\
\hline \multirow{5}{*}{$\begin{array}{c}\text { Santa } \\
\text { Cruz }\end{array}$} & Mean & 0.52 & 1.64 & 0.53 & 0.04 & 0.87 & 0.13 & 1.31 & 0.09 & 0.05 & 0.64 \\
\hline & STD & 0.53 & 0.25 & 0.57 & 0.03 & 0.12 & 0.09 & 0.37 & 0.09 & 0.02 & 0.16 \\
\hline & Median & 0.33 & 1.69 & 0.29 & 0.03 & 0.92 & 0.11 & 1.36 & 0.06 & 0.03 & 0.64 \\
\hline & Max. & 3.53 & 2.15 & 3.48 & 0.17 & 0.99 & 0.24 & 2.4 & 0.20 & 0.21 & 0.98 \\
\hline & Min. & 0.06 & 1.49 & 0.05 & 0.00 & 0.18 & 0.03 & 1.05 & 0.01 & 0.01 & 0.17 \\
\hline \multirow{5}{*}{ La Paz } & Mean & 0.12 & 0.95 & 0.07 & 0.05 & 0.55 & 0.09 & 0.84 & 0.04 & 0.04 & 0.48 \\
\hline & STD & 0.06 & 0.30 & 0.06 & 0.02 & 0.15 & 0.04 & 0.31 & 0.03 & 0.02 & 0.13 \\
\hline & Median & 0.11 & 0.95 & 0.05 & 0.05 & 0.53 & 0.08 & 0.82 & 0.04 & 0.04 & 0.48 \\
\hline & Max. & 0.46 & 1.69 & 0.44 & 0.13 & 0.95 & 0.16 & 1.92 & 0.14 & 0.08 & 0.89 \\
\hline & Min. & 0.03 & 0.74 & 0.01 & 0.01 & 0.17 & 0.02 & 0.62 & 0.01 & 0.01 & 0.17 \\
\hline
\end{tabular}

251 Table 1: Mean, standard deviation (STD), median and maximum (Max.) and minimum (Min.) values of aerosol 252 optical depth (AOD), Angstrom parameter $(\alpha)$ between 440 and $870 \mathrm{~nm}$, fine $\left(A O D_{\text {fine }}\right)$ and coarse $\left(A O D_{\text {coarse }}\right)$ mode 253 aerosol optical depths and relative contribution of fine mode to total optical depth ( $\eta$ ). Data are presented for 254 biomass and non biomass-burning seasons for the stations in the lowlands (Cuiaba, Ji Parana, Rio Branco and Santa 255 Cruz) and in the highlands (La Paz). Reference wavelength for $A O D, A O D_{\text {fine, }}, A_{\text {coarse }}$ and $\eta$ is $500 \mathrm{~nm}$.

256

The differences in the maximum values of AODs among the different biomass-burning

257 seasons imply a multi-year variability in fire emissions, which is consistent with the large

258 standard deviation of AODs reported in Table 1. Emissions of smoke particles from biomass

259 burning are mostly associated with human activities. Examples of this are fires that are used for

260 forest clearing by small farmers and plantation owners who clear understory shrubbery and cut 
261 forest trees. The area is burned a few months after the clearing, and, although the fires are 262 intended to only burn in limited areas, they sometimes spread beyond the targeted agricultural 263 zone and consume pristine rainforest (e.g. Torres et al., 2010). The extent and intensity of the 264 burned areas can vary from year to year.

To show that the data used are predominately cloud-free, Figure 3 shows $\alpha(440-870)$ versus $\operatorname{AOD}(500)$ for lowland stations. Cloud-affected data typically present $\alpha(440-870)<0.5$

267 (O'Neill et al., 2003). In particular, AODs $>2$ are associated with $\alpha(440-870)$ values that are 268 generally> 1.2, a value which suggests minimal cloud contamination in the measurements. 269 Moreover, the number of photocounts is large enough to guarantee the quality of the 270 measurements: for very high AODs the number of photocounts registered by the AERONET 271 instruments ranged from about 50 to 20 counts for $500 \mathrm{~nm}$ AODs of 4 and 6 respectively at the 272 Cuiaba site, while the minimum count required for good AOD measurement is 10 (Sinyuk et al., 273 2012).

274 The analyses of $\eta$ is useful for detecting when AOD measurements are affected by thin 275 and stable cirrus clouds (O'Neill et al., 2003). Measurements affected by cirrus clouds present 276 low $\eta$ because these clouds are formed by big ice crystals. Indeed, for aerosol with fine mode 277 predominance and not affected by cirrus $\eta$ present high values. This approach can be applied for 278 smoke particles. The analyses performed of $\eta$ values for Figure 3 data reveal that measurements 279 with AOD $>2.0$ (71 days totally) present $\eta>0.85$, suggesting no presence of clouds. For $1<$ 280 AOD $<2$ were registered 220 days of measurements, and it is found that $94 \%$ with $\eta>0.9$, and 281 only 4 days of measurements with $\eta<0.75$ that could be associated with influence of thin cirrus 282 clouds. Finally, for 394 days of measurements that presented $0.5<$ AOD $<1$, were registered $28382 \%$ of cases with $\eta>0.9$ and $94 \%$ with $\eta>0.8$. The rest of the cases with lower $\eta$ can be 
associated with aerosol influenced by coarse particles, although the presence of thin cirrus clouds cannot be discarded.

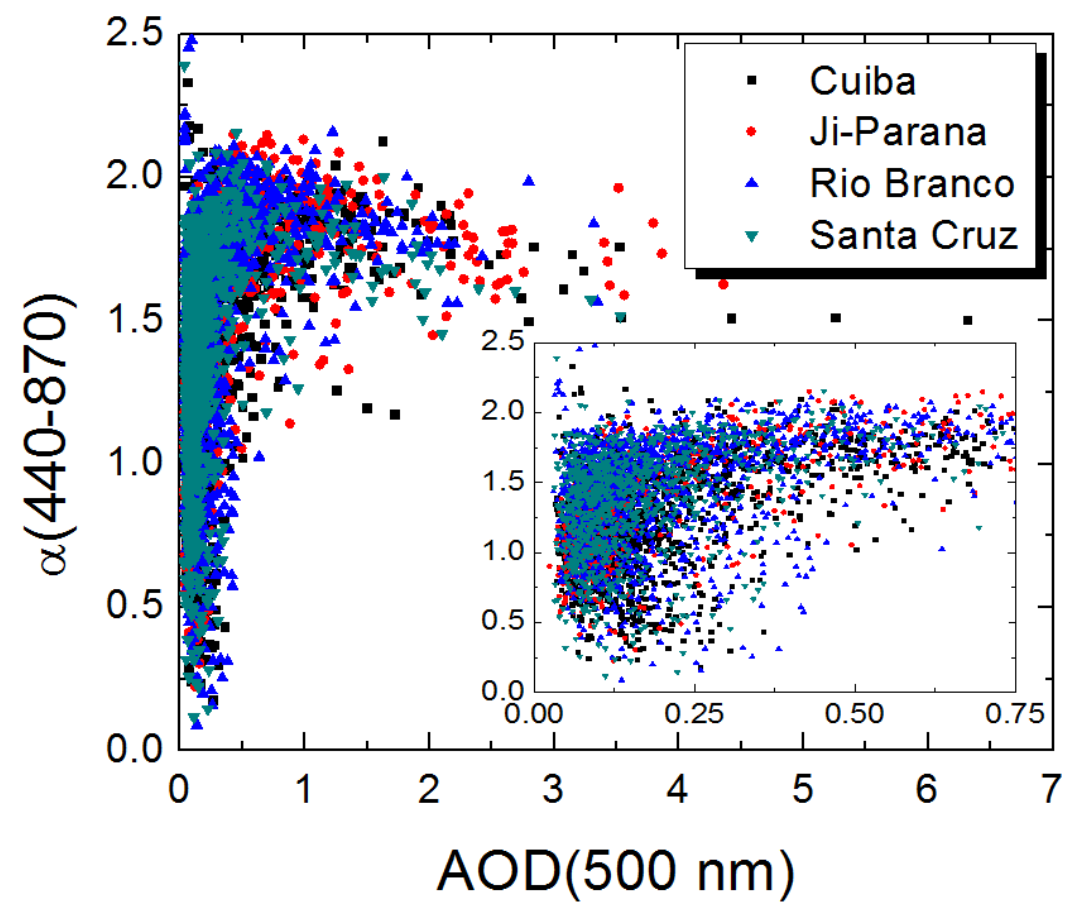

Figure 3: Angstrom exponent versus AOD for the measured points of Figure 2.

The maximum values reported in Figure 2 represent some of the largest values ever 289 registered in the AEROENT Version 2 database (http://aeronet.gsfc.nasa.gov/cgi290 bin/climo_menu_v2_new). The mean values during the biomass-burning season are also among 291 the largest monthly mean climatological values. Schafer et al., (2008) registered similar values 292 using stations located in the Amazon basin. Comparably high AOD values were also reported for 293 African biomass-burning by Eck et al., (2003, 2013). Moreover, the occurrence of very high 294 AOD values over the extended periods of time that we have reported here are only obtained in 295 very polluted parts of Asia (e.g. Eck et al., 2010), very dusty areas in the Sahara (e.g. Guirado et 296 al., 2014) and the Arabian Peninsula (e.g. Kim et al., 2011). 
For the highland La Paz station the AOD increased during the August-October period 298 from mean values around 0.09 to 0.12 (Table 1), but the AOD values are much lower than those 299 in the lowlands. Although the fine mode is still predominant, the contribution of coarse mode to 300 the total AOD cannot be ignored. The frequency histograms of $\operatorname{AOD}(500)$ for each station are 301 given in Figure 4, and they show that only $7 \%$ of data at La Paz present AOD > 0.4 while for the 302 stations of Cuiaba, Ji Parana, Rio Branco and Santa Cruz these percentages are of 45\%, 59\%, $30344 \%$ and $41 \%$ respectively. That indicates the greater contribution of biomass-burning particles 304 in the lowlands to the total aerosol load and to the aerosol seasonal changes.
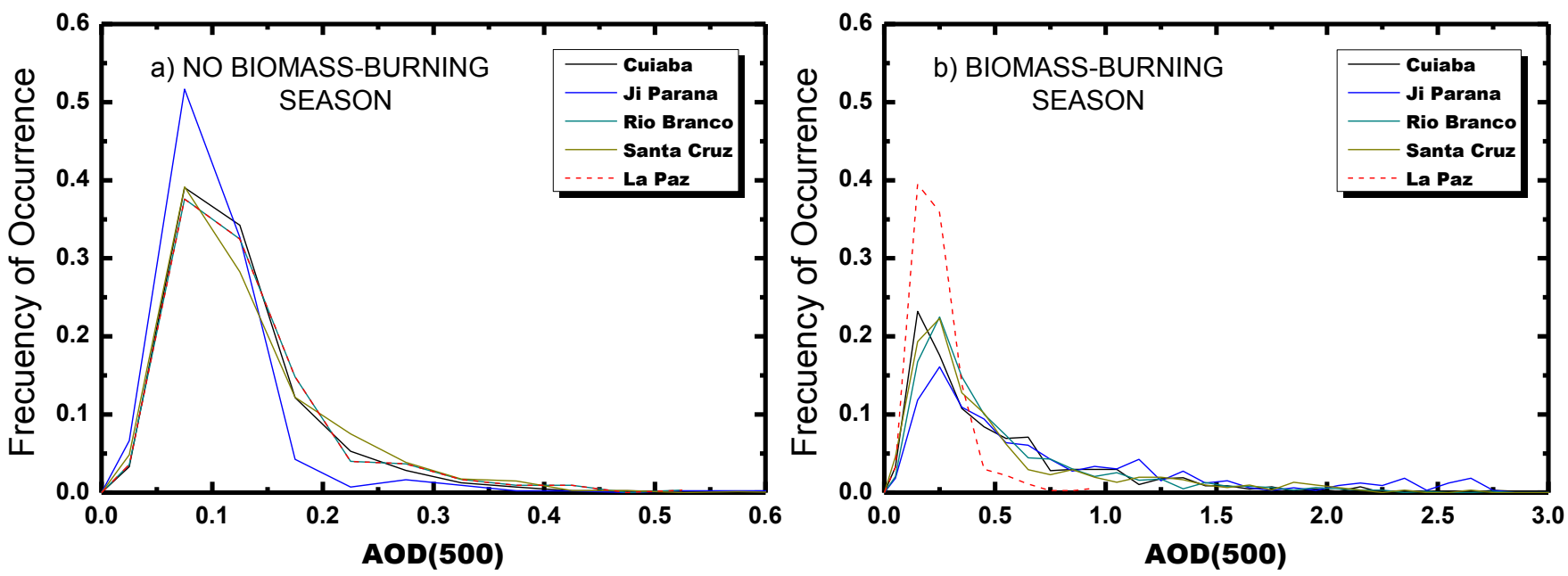

Figure 4:Frequency histograms of aerosol optical depth at $500 \mathrm{~nm}(\mathrm{AOD}(500))$ for (a) no biomass-burning and (b) biomass-burning seasons.

Multi-wavelength lidar measurements in the central Amazon made by Baars et al., (2012)

308 showed that smoke plumes can reach altitudes up to $5 \mathrm{~km}$. During the burning season, the 309 reduced vegetation in the highlands implies few fires, while the large AODs in the lowlands 310 suggests that transport of smoke particles from nearby Amazonia is the a important source of 311 particles in the highlands. The Andes chain in the tropics is therefore a barrier for the transport of 312 smoke to the Pacific Ocean, in agreement with the results of Bourgeois et al., (2015) using 313 CALIPSO data. 
317 within a given rectangle. The horizontal line segment in the rectangle is the median. The top

318 limit (top of the rectangle) represents the $75^{\text {th }}$ percentile $(P 75)$ and the bottom limit the $25^{\text {th }}$

319 percentile $(P 25)$. The lines perpendicular to the boxes are the $1^{\text {st }}(P 1)$ and $99^{\text {th }}(P 99)$ percentiles,

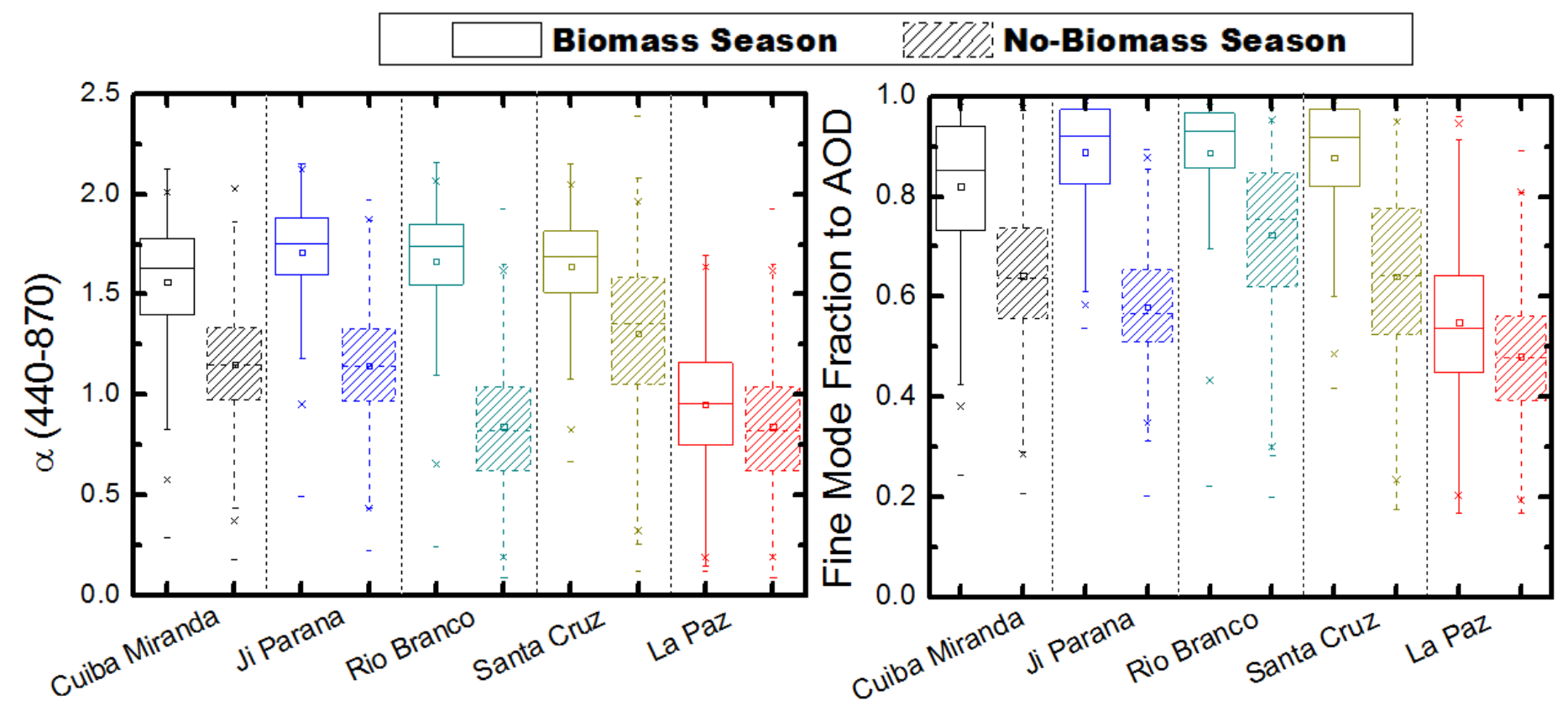

Figure 5:Box-Whisker plots during the biomass and no biomass-burning seasons of the Angstrom parameter $\alpha(440-$ 870) and fine mode fraction to AOD for the lowlands stations (Cuiaba Miranda, Ji Parana, Rio Branco and Santa Cruz) and highlands station (La Paz). In the Box-Whisker plots, the mean is represented by a very small open square within a given rectangle. The horizontal line segment in the rectangle is the median. The top limit (top of the rectangle) represents the $75^{\text {th }}$ percentile $(P 75)$ and the bottom limit the $25^{\text {th }}$ percentile $(P 25)$. The lines perpendicular to the boxes are the $1^{\text {st }}(P 1)$ and $99^{\text {th }}(P 99)$ percentiles, and the crosses represent the maximum and 
Figure 5 shows very high values of $\alpha(440-870)$ in the lowlands during the biomass-

332

burning seasons, with mean values of 1.5-1.7 which are similar to biomass-burning values reported in the literature (e.g. Dubovik et al., 2002; Schafer et al. 2008) and, along with the values of $\eta$ above 0.80 , indicate a predominance of fine particles. Lower values of $\alpha(440-870)$, characterized by large standard deviations, are observed for the non-biomass burning seasons. The mean values also vary significantly among stations (from 0.86 at Rio Branco to 1.36 at Santa Cruz). These results, plus the fact that the values of $\eta$ vary between 0.7 and 0.5 , indicate a lack of predominance of fine or coarse mode in the wet season. Indeed, a mixture of different particles predominates. On the other hand, the mean Angstrom Exponent values of 0.94 and 0.85 for the biomass and non-biomass burning seasons, respectively at the highland station of La Paz, are not significantly different after considering the standard deviation. The same is true for $\eta$, with mean values of 0.55 and 0.48 respectively. These La Paz values of $\alpha(440-870)$ and $\eta$ cannot, accordingly, be associated with large predominance of either fine or coarse mode.

The multi-year and seasonal variability of AOD and $\alpha(440-870)$ in the highland station is illustrated in Figure 6 as a function of the day of the year. Mean values are represented by dots and standard deviations by vertical lines. These values are the result of averaging AOD for each day of the year in different years. During the biomass-burning season mean AOD at $500 \mathrm{~nm}$ is of $0.12 \pm 0.06$, but the standard deviations of the means indicate AOD peaks of up to 0.35 , and are typical values associated with the transport of biomass-burning particles to high mountain places (e.g. Perez-Ramirez et al., 2008). For other high mountain sites in the Himalayas during the premonsoon season, values of up to 0.1 are reported at elevations of $\sim 5000 \mathrm{~m}$ a.s.l. (Marcq et a., 2010) and up to 0.5 at elevations of $~ 2000 \mathrm{~m}$ a.s.l. (Dumka et al., 2008). Therefore, the values obtained in La Paz station are similar to high-mountain Himalayan sites affected by the transport 
354 of pollutants. The large standard deviations of AODs in the biomass-burning season also indicate

355 large variability, which suggests that the arrival of smoke particles occurs during sporadic events

356 rather than as part of a continuous. AODs values during the other seasons (especially in the

357 April-July period), are $\sim 0.1$ and are considered as background conditions (local

358 origins).Therefore, biomass-burning transport to high mountains can induce AOD values of up to

359 five times the average background conditions. In section 3.4, we study several such events in

360 detail. The period November-March (wet season) exhibits large variability, which might be

361 explained by meteorological factors such as wet deposition and by the less robust statistics of the

362 smaller database associated with that period.
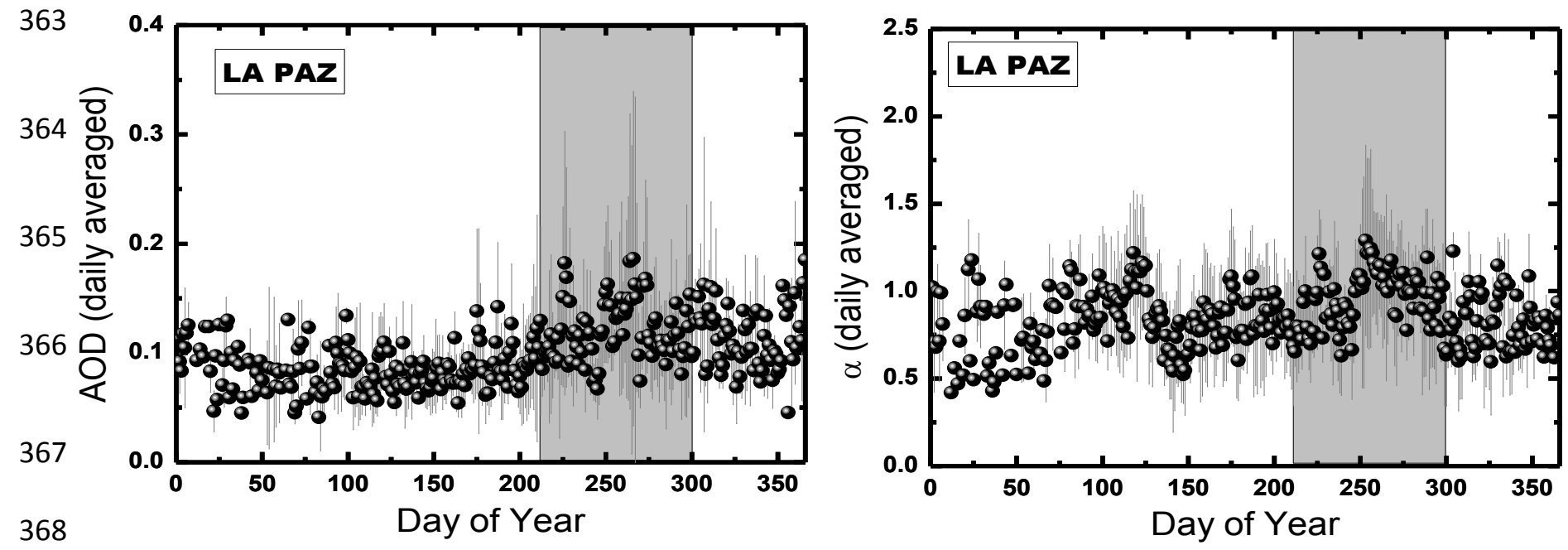

369 Figure 6: Mean AOD and Angstrom parameter ( $\alpha(440-870))$, including standard deviations, for every 370 day of the year for the highland station of La Paz. The areas shadowed in light grey represent the 371 biomass-burning seasons.

The parameter $\alpha(440-870)$ shows mean values that are not significantly different during

373 the biomass burning season as compared with the other seasons (Figure 6b). This suggests that

374 the particle type predominance during the biomass-burning season is similar to that in other

375 seasons (which are probably dominated by aerosols of local origin). Actually, during the

376 biomass-burning season, mean $\alpha(440-870)$ values are around 1.0 while values for background 
377 conditions (focussing on the April-July period with mean AODs of $\sim 0.09) \alpha(440-870)$ are around 378 0.85. In the wet season (November-March), the larger variability observed in Figure 6 can be 379 explained by the low AODs $(<0.05)$ which implies larger uncertainties in $\alpha(440-870)$.

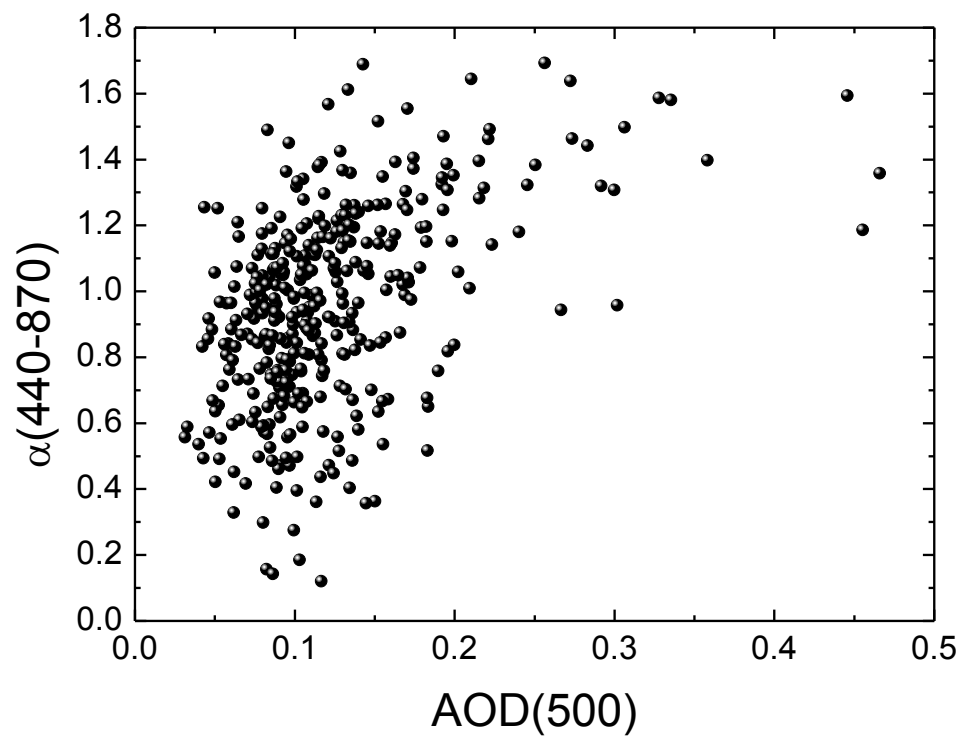

380

Figure 7: Angstrom exponent versus AOD in the highlands station of La Paz.

The frequency of sporadic smoke events transported to La Paz can be observed in the $\alpha(440-870)$ versus AOD graph of Figure 7 (whose dataset is limited to the biomass-burning season).In order to discriminate AOD contributions associated with thetransport of smoke from background AODs, we established AOD > 0.14, which is the mean plus standard deviation value during the non biomass-burning season (Table 1), as a criterion for classifying intense smoke events. Analyses of Figure 7 data indicate that only $10 \%$ of the measurements acquired during the biomass-burning season exceed this threshold. The cases of smoke transport are characterized by a considerably higher $\alpha(440-870)(1.4 \pm 0.2)$ versus the background. Since there is no other extra source than episodic biomass-burning aerosols (emissions by local sources are almost constant throughout the year), the large differences in the Angstrom exponent associated 
392 with smoke between lowlands $(\sim 1.8)$ and highlands $(\sim 1.4)$ suggest changes in smoke particles

393 during their transport to the highlands. This could also suggest a larger influence of local coarse 394 mode particles at La Paz since the maximum AOD values are much lower there than in the 395 Amazonian Basin.

\subsection{Biomass-burning and precipitation rates}

Table 2 reports the rainfall difference between values registered and climatological values for each season. Such difference is defined here as rainfall anomaly. Data used are from TRMM satellite (http://trmm.gsfc.nasa.gov) for the period 2002-2014 in the study area (10-20 South, $50-70^{\circ}$ West.). The mean of the TRMM data are taken as the climatological values and are

401 shown in parentheses. The 'wet' period was taken to be November-March, the 'dry' period to be 402 April-July while the biomass burning period was taken as August-October.

An anomalous precipitation increase during the wet period can increase the amount of 404 vegetation to be burned during the biomass-burning season (Uhl et al., 1998). Increases in precipitation during the biomass-burning period favors particle wet deposition and the shortening

406 of aerosol lifetimes (Freitas et al., 2005). An increase in aerosol loads can be expected for the dry 407 and biomass burning periods due to unusually dry conditions that intensify fire activity. Such 408 links with precipitation seem to be clear for the intense biomass-burning activity (as represented 409 by AOD amplitude in Figure 2) registered in 2005-2010: positive rainfall anomalies in the wet 410 season could have increased the amount of biomass that could be burned in the following 411 burning season, while negative rainfall anomalies in the dry and / or burning seasons could have 412 favored fire activity. An exception to this pattern is 2009, which exhibits positive rainfall 413 anomalies during the dry and biomass-burning seasons and therefore lowers AODs. However, in 4142008 a strange behavior was observed in that dry conditions were present but lower AOD values 
reported by Torres et al., (2010) using OMI space-borne sensor data.

\begin{tabular}{|c|c|c|c|c|}
\hline & \multicolumn{3}{|c|}{ Rainfall Anomaly $(\mathrm{mm})$ for different seasons } & \multirow{2}{*}{$\begin{array}{c}\text { Mean AERONET } \\
\text { AOD during } \\
\text { Biomass-Burning } \\
\text { Season }\end{array}$} \\
\hline & $\begin{array}{c}\text { Wet } \\
(199.70 \mathrm{~mm})\end{array}$ & $\begin{array}{c}\text { Dry } \\
(42.97 \mathrm{~mm})\end{array}$ & $\begin{array}{c}\text { Biomass-Burning } \\
(67.16 \mathrm{~mm})\end{array}$ & \\
\hline 2000 & 2.74 & -3.64 & -2.06 & $0.39 \pm 0.29$ \\
\hline 2001 & -9.46 & 3.56 & 4.74 & $0.47 \pm 0.30$ \\
\hline 2002 & -16.16 & 1.91 & -5.02 & $0.49 \pm 0.37$ \\
\hline 2003 & -20.75 & 2.81 & 12.32 & $0.42 \pm 0.27$ \\
\hline 2004 & -2.97 & -4.99 & -4.35 & $0.44 \pm 0.38$ \\
\hline 2005 & 12.08 & -4.05 & 5.28 & $0.80 \pm 0.70$ \\
\hline 2006 & 1.69 & -9.01 & 0.72 & $0.62 \pm 0.59$ \\
\hline 2007 & 35.70 & -12.51 & -6.5 & $1.18 \pm 1.00$ \\
\hline 2008 & 9.20 & -12.07 & -1.30 & $0.43 \pm 0.29$ \\
\hline 2009 & 10.02 & 7.27 & 0.17 & $0.20 \pm 0.11$ \\
\hline 2010 & 3.41 & -11.91 & -5.91 & $0.95 \pm 0.67$ \\
\hline 2011 & 5.77 & -11.57 & -6.70 & $0.32 \pm 0.21$ \\
\hline 2012 & -13.08 & 7.28 & -12.94 & $0.40 \pm 0.27$ \\
\hline 2013 & 41.18 & 9.13 & 15.94 & $0.29 \pm 0.19$ \\
\hline
\end{tabular}

Table 2: Precipitation anomaly for 'wet' (November-March), 'dry' (April-July) and biomass-burning seasons (August-October). The mean climatological values are in parentheses. The anomaly is defined as the difference between registered and climatological values for each season. All precipitation data were acquired by the TRMM satellite and are the average over the area 10-20 South and 50-70 West. The AOD column is the average, at $500 \mathrm{~nm}$, across the biomass burning season for the lowland stations at Cuiaba, Ji Parana, Rio Branco and Santa Cruz. The "Wet" column represents data whose November to March period started in the previous year.

The 2002-2004 period (except for the dry period of 2004) exhibits an opposite pattern, with a precipitation deficit in the wet season and positive rainfall anomalies in the dry and burning seasons. The lower AODs for these years are broadly coherent with the concepts presented above on the relationship between rainfall anomaly and fire activity. However, after 2011 the type of reasoning that we have employed above to make the link between rainfall anomaly and fire activity is not followed, as a continuous reduction of AODs and fire activity has been observed independently of precipitation. Specific regulations and/or economic forces as 
431 suggested by Koren et al., $(2007,2009)$ could have helped to reduce fire activity. More years of

432 data and perhaps different level of correlation analyses have to be investigated.

\subsection{Aerosol Particle Sizes}

Figure 8 shows the mean particle volume size distributions from AERONET almucantar retrievals for the study stations, separated into biomass and non-biomass burning seasons. Different scales are used in the Y-axes between both seasons to better visualize size distribution

437 shapes. This figure indicates that during the biomass-burning season the fine mode largely 438 predominates for the lowland stations. Very similar size distributions for biomass-burning have 439 been reported in the literature (e.g. Eck et al., 2003; Schafer et al., 2008). However, in the 440 highlands the size distribution exhibits two modes with approximately the same volumetric 441 relevance, although that does not imply that both modes have the same optical effect (in the

442 visible spectral range, for the same volume, $\mathrm{AOD}_{\text {fine }}$ is larger than $\left.\mathrm{AOD}_{\text {coarse}}\right)$. This is broadly 443 consistent with the previous results of the $\alpha(440-870)$ and $\eta$ analysis: the coarse mode could be 444 associated with the injection of dust particles from the Andean Altiplano, either by traffic re445 suspension or regional winds: On-going studies with in-situ instrumentation are revealing that 50 $446 \%$ of PM10 particles are associated with mineral dust (Alastuey et al., 2017). Fine mode particles 447 are likely associated with anthropogenic activity (e.g. vehicle emissions) and with the transport 448 of smoke particles. On the other hand, during the non-biomass burning season, the maxima of 449 volume size distributions are lower in accordance with the lower AODs. It is also observed for 450 all the stations that no mode predominates, but rather, there is an apparent mixture of different 451 types of particles. This result is also consistent with the intermediate values of $\alpha(440-870)$ and $\eta$ 452 noted above. For La Paz, the two modes are explained by the same mechanism noted for the 
453 biomass-burning case, although the fine mode volume is smaller due to the absence of 454 transported smoke particles.
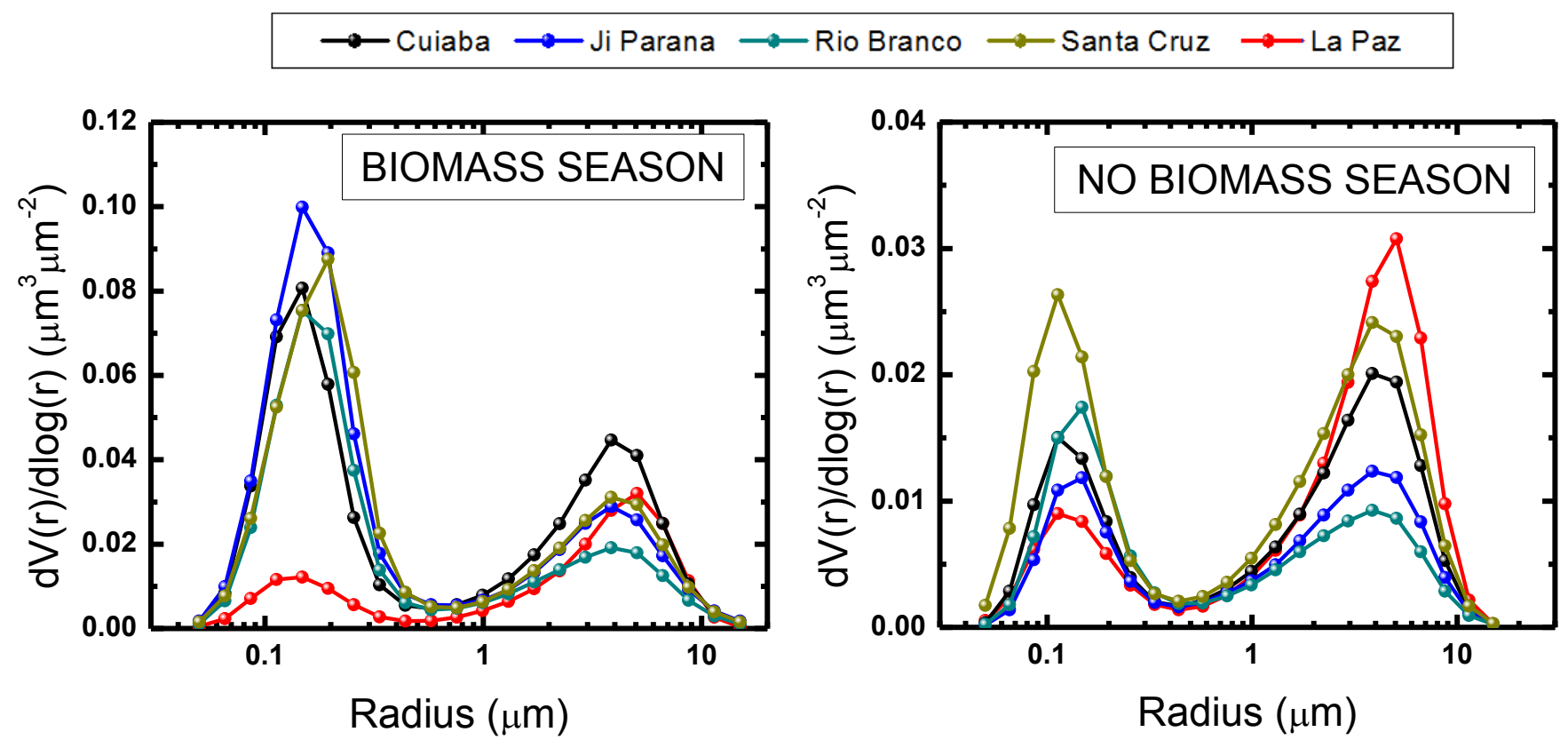

455

$456 \quad$ Figure 8: Mean columnar volume size distributions for the lowland stations and highland (La Paz), both for biomass 457 and no biomass-burning seasons.

458 The stations in the lowlands, Santa Cruz and Cuiaba show a relevant coarse mode, which 459 is present in both seasons. This coarse mode can be associated with different local sources of 460 dust. Transport of dust from river beds is a possible explanation, as is illustrated in Figure 9 461 which shows a true color image for the lowland area on $12^{\text {th }}$ September 2016 . The image is 462 composed by the different images acquired by MODIS (Aqua and Terra) and VIIRS space 463 systems (images available at http://go.nasa.gov/2eULwP1). The low level jet which runs parallel to 464 the mountain with southerly direction is observed from the clouds and smoke transport patterns. 465 Making a zoom on the river areas, transported dust plumes are observed. Injections of dust from 466 riverbeds have been also observed in Alaska (Crusius et al., 2011). In South America, other 467 regions that could be responsible for transport of dust to the lowlands is the Chaco plain that 
spreads to the Andes foothills through Bolivia, Argentina and Paraguay, and include some of the

469 largest tributary rivers and delta rivers in the world (Latrubesse et al., 2012). From more southern

470 locations, injections of salt particles in the atmosphere have been observed from the Mar

471 Chiquita Lake (Bucher and Stein, 2016). The Andean region has other possible sources of dust

472 particles such as the Salar de Uyuni or the Atacama Desert (Gaiero et al., 2013). The high

473 latitudes of these two places could have more influence on the injection of particles in the

474 lowlands. Nevertheless, more analysis is needed to study the impact and properties of dust

475 particles in the tropical region of South America.

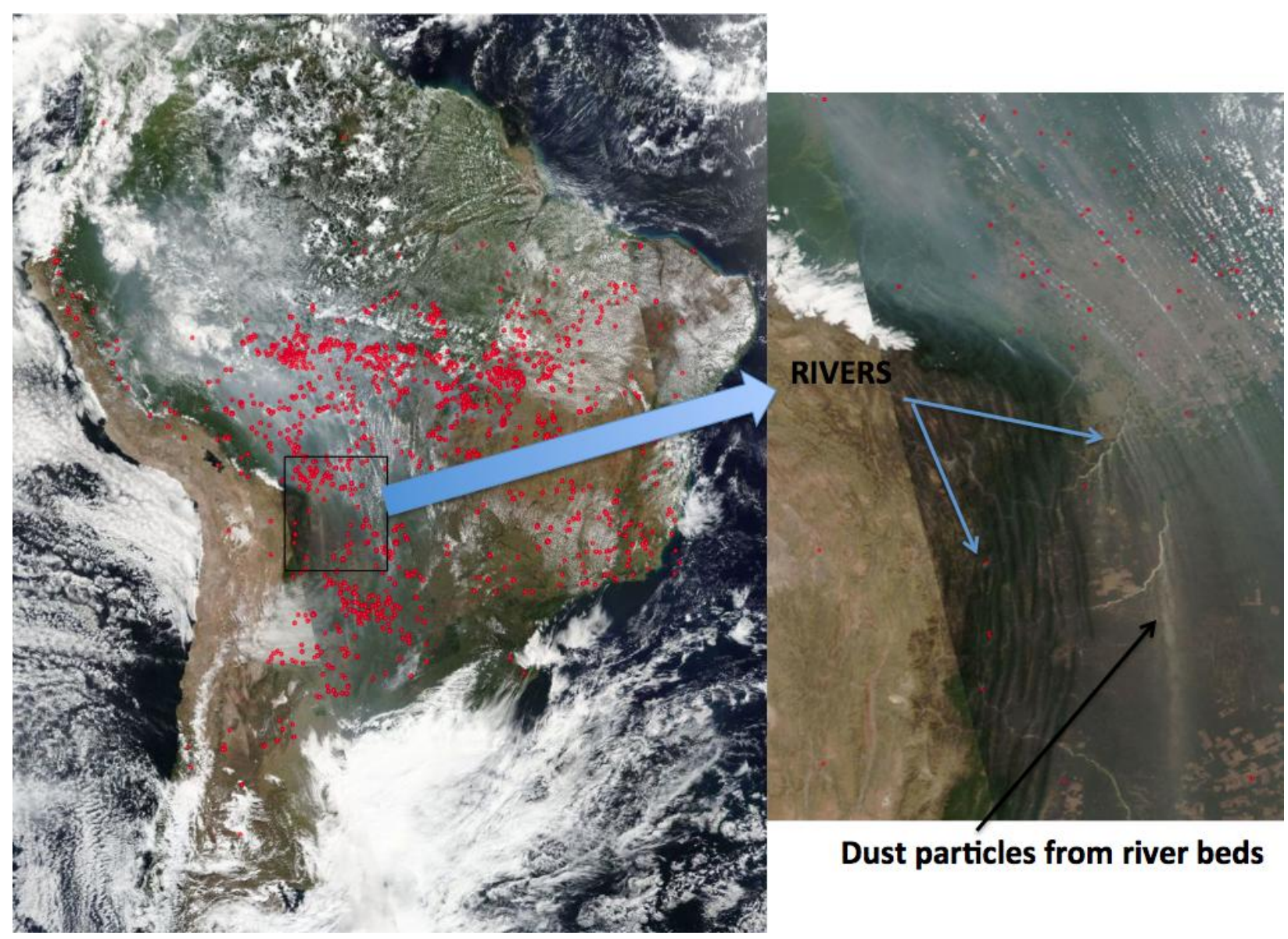

477 Figure 9: True color image of South America from the composition of images from MODIS (Aqua and Terra) and 478 VIIRS space-systems for $12^{\text {th }}$ September 2016. A zoom is made on the lowlands in Bolivia. 

stations in Bolivia are available for more than 10 years, both for the lowlands and the highlands. For the wet period (November-March) when most precipitation occurs, the highest values of 483 ware found (around $19 \mathrm{~g} / \mathrm{Kg}$ and $8 \mathrm{~g} / \mathrm{Kg}$ for the lowlands and highlands, respectively). For the 484 dry period (April-July) with very little precipitation the lowest values are found (around $14 \mathrm{~g} / \mathrm{Kg}$ 485 and $4 \mathrm{~g} / \mathrm{Kg}$ for the lowlands and highlands, respectively). However, for the biomass-burning 486 season values are in the middle (around $16.5 \mathrm{~g} / \mathrm{Kg}$ and $5.5 \mathrm{~g} / \mathrm{Kg}$ for the lowlands and highlands, 487 respectively) indicating the presence of enough water vapor in the atmosphere to favor cloud 488 development which therefore, reduces the number of measurements that fulfil the completely 489 cloud-free sky AERONET criteria for retrieving aerosol microphysical properties. Therefore, due 490 to AODs measurements only require direct sun measurements, LE retrievals and ONeill et al., 491 (2005) methodology are used to obtain $r_{\text {eff }}$ and $r_{\text {fine }}$, respectively, and complement AERONET 492 retrievals. Actually, during all of the biomass-burning seasons, the number of Level 2.0 retrievals 493 obtained using the almucantar retrieval was 738, 750, 1017, 262 and 206 for the Rio Branco, Ji 494 Parana, Cuiaba, Santa Cruz and La Paz stations, respectively. The number of higher temporal 495 resolution (spectral) retrievals using the LE technique were respectively 16189, 6343, 25017, 4966719 and 18220 - this is a significant increase in the number of retrievals for the La Paz station 497 compared with the AERONET almucantar retrievals.

To understand the spatial differences in retrieved particle radii, station by station, Box499 Whisker plots of $r_{\text {eff }}$ and $r_{\text {fine }}$, separated into biomass-burning and non biomass-burning seasons, 500 are shown in Figure 10. Table 3 summarizes the main statistical parameters of these plots. Linear 501 Estimation and O'Neill et al., (2005) retrievals are used. Similar patterns and statistics were 502 obtained using only AERONET retrieval data, although less robust statistically. During the 
503 biomass-burning season the similarity of the mean values and the low standard deviations of both 504 parameters in the lowlands is remarkable: both of these comparisons indicate an approximate 505 homogeneity in the biomass-burning process with respect to particle size. The relatively large 506 variability in the non biomass-burning season can be explained by the highly variable 507 background aerosol conditions with mixtures of different aerosol types prevailing. The typically 508 larger uncertainties in $r_{\text {eff }}$ and $r_{\text {fine }}$ for low aerosol loads can also explain some of the increased 509 variability. The Santa Cruz station shows larger $r_{\text {eff }}$ during the non biomass-burning season 510 which, as noted before, could be associated with coarse particles transported from local riverbeds 511 as described in association with Figure 9. The highlands show systematically larger values of $r_{\text {eff }}$ and $r_{\text {fine }}$ independently of the 513 season. The slightly lower values of both parameters during the biomass-burning season can be 514 explained by the transport of smoke particles which, as previously noted, are predominantly fine 515 mode. Aging of the transported particles (e.g. Eck et al., 2003; O'Neill et al., 2008b) could 516 explain the larger $r_{\text {eff }}$ and $r_{\text {fine. }}$. The permanent coarse mode associated with dust on the Altiplano 517 could also have an influence in terms of an increase in $r_{\text {eff. }}$ The wind regime in the high 518 mountains can favour accumulation of particles and can explain the larger values of $r_{\text {fine }}$ 519 compared to the lowlands (Vuille, 1999). 521 represent $r_{\text {eff }}$ and $r_{\text {fine }}$ versus the AOD at $500 \mathrm{~nm}$ for the combination of all lowland data. Again, 522 Linear Estimation and O'Neill et al., (2005) are used for the retrievals of $r_{\text {eff }}$ and $r_{\text {fine, }}$, 523 respectively. We constrained the data plotted to conditions of AOD > 1.0 in order to limit the 524 study to smoke particles only. Higher temporal-resolution retrievals of $r_{\text {eff }}$ and $r_{\text {fine }}$ because do 525 provide larger datasets and also do allow retrievals for very high AODs which and may well be 
526 favoured in the case of partly cloudy skies (see our argument above for the greater probability of

527 clouds being associated with smoke aerosols).

528

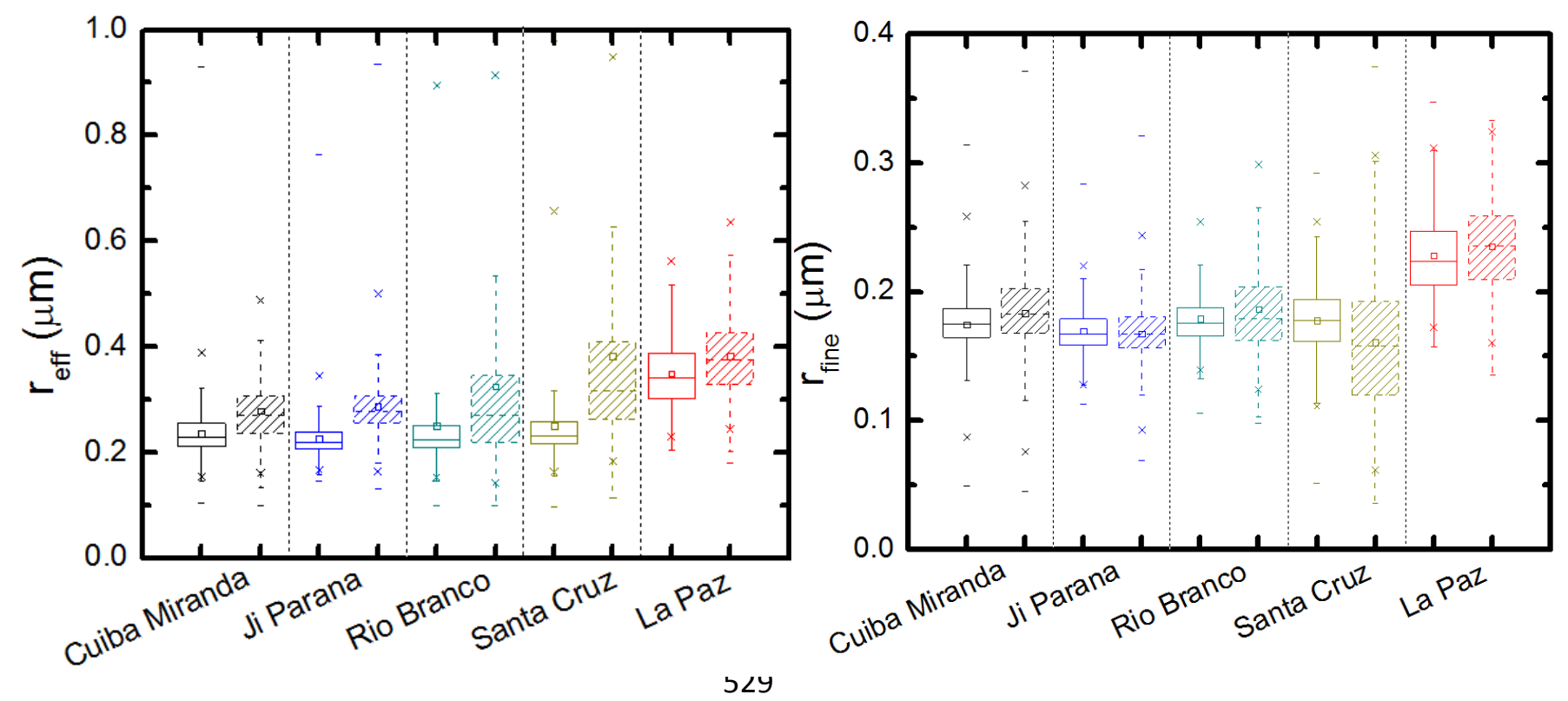

Figure 10: Box-Whisker plots during the biomass and no biomass-burning seasons of the effective radius $\left(r_{\text {eff }}\right)$ and fine mode effective radius $\left(r_{\text {fine }}\right)$ for the lowland stations (Cuiaba Miranda, Ji Parana, Rio Branco and Santa Cruz) and the highland station (La Paz). In the Box-Whisker plots, the mean is represented by a very small open square within a given rectangle. The horizontal line segment in the rectangle is the median. The top limit (top of the rectangle) represents the $75^{\text {th }}$ percentile $(P 75)$ and the bottom limit the $25^{\text {th }}$ percentile $(P 25)$. The lines perpendicular to the boxes are the $1^{\text {st }}(P 1)$ and $99^{\text {th }}(P 99)$ percentiles, and the crosses represent the maximum and minimum values respectively.

537 Figure 11 shows linear trends of $r_{\text {eff }}$ and $r_{\text {fine }}$ with AOD increases. Similar patterns were obtained

538 by using the operational AERONET almucantar retrieval algorithm, although the lower number

539 of data introduced more uncertainty in the linear regressions. Actually, maximum AODs for

540 AERONET retrievals were for $\sim 3.2$, while for data of Figure 11 that maximum is for $\sim 6.0$. Root-

541 mean-square differences are $\sim 0.027$ for $r_{\text {eff }}$ and $\sim 0.016$ for $r_{\text {fine. The results of the linear fits }}$

542 shown in Figure 11 indicate that $r_{\text {fine }}$ is nominally more sensitive to changes in AOD (the slope of

543 the regression line is larger). The difference, for example, between the minimum and maximum

544 AOD values of 1.0 and 6.0 is $0.035 \mu \mathrm{m}$ for the associated $r_{\text {eff }}$ regression line. This is small 


\begin{tabular}{|c|c|c|c|c|c|}
\hline & & $r_{\text {eff }}$ & $r f_{\text {ine }}$ & $r_{\text {eff }}$ & $r f_{\text {ine }}$ \\
\hline & & \multicolumn{2}{|c|}{$\begin{array}{l}\text { Biomas- } \\
\text { Burning }\end{array}$} & \multicolumn{2}{|c|}{ No Biomass } \\
\hline \multirow{4}{*}{ Cuiaba } & Mean & 0.24 & 0.18 & 0.27 & 0.20 \\
\hline & STD & 0.05 & 0.03 & 0.07 & 0.04 \\
\hline & Median & 0.23 & 0.18 & 0.27 & 0.20 \\
\hline & Max. & 0.93 & 0.31 & 0.99 & 0.38 \\
\hline \multirow{4}{*}{ Ji Parana } & Mean & 0.22 & 0.17 & 0.29 & 0.16 \\
\hline & STD & 0.03 & 0.02 & 0.06 & 0.05 \\
\hline & Median & 0.22 & 0.17 & 0.28 & 0.17 \\
\hline & Max. & 0.76 & 0.28 & 0.93 & 0.35 \\
\hline \multirow{4}{*}{$\begin{array}{c}\text { Rio } \\
\text { Branco }\end{array}$} & Mean & 0.25 & 0.18 & 0.32 & 0.19 \\
\hline & STD & 0.11 & 0.02 & 0.18 & 0.03 \\
\hline & Median & 0.22 & 0.17 & 0.27 & 0.18 \\
\hline & Max. & 1.05 & 0.32 & 1.01 & 0.38 \\
\hline \multirow{4}{*}{$\begin{array}{l}\text { Santa } \\
\text { Cruz }\end{array}$} & Mean & 0.25 & 0.18 & 0.38 & 0.13 \\
\hline & STD & 0.08 & 0.03 & 0.19 & 0.06 \\
\hline & Median & 0.23 & 0.17 & 0.31 & 0.12 \\
\hline & Max. & 0.97 & 0.28 & 1.17 & 0.39 \\
\hline \multirow{4}{*}{ La Paz } & Mean & 0.34 & 0.22 & 0.38 & 0.24 \\
\hline & STD & 0.07 & 0.03 & 0.08 & 0.04 \\
\hline & Median & 0.34 & 0.16 & 0.37 & 0.23 \\
\hline & Max. & 1.14 & 0.35 & 1.08 & 0.51 \\
\hline
\end{tabular}

546

547 Table 3: Mean, standard deviation (STD), median and maximum (Max.) values of effective radius ( $r_{\text {eff }}$ ) and effective 548 radius of the fine mode $\left(r_{\text {fine }}\right)$. Data are presented for biomass and no biomass-burning seasons for the lowland 549 stations (Cuiaba, Ji Parana, Rio Branco and Santa Cruz) and the highlands (La Paz).

550 compared with the $r_{\text {eff }}$ values. The analogous $r_{\text {fine }}$ calculation (a regression line increase of 0.065 $551 \mu \mathrm{m}$ for the same range of AODs),corresponds to a change of approximately $40 \%$. Such large 552 aerosol loads favour the accumulation of particles in the atmosphere and, can therefore favor 553 particle aging. For example, larger $r_{\text {fine }}$ and $r_{\text {eff }}$ have been found during the night due mainly to 554 particle accumulations (e.g. Pérez-Ramírez et al., 2012). Also, coagulation rates increase as 555 particle concentration (or AOD) increases (Colarco et al., 2003). The observed trend of 
556 increasing fine mode particle size in Amazonia as AOD increases is consistent with the findings

557 of Schafer et al. (2008) from AERONET almucantar retrievals.

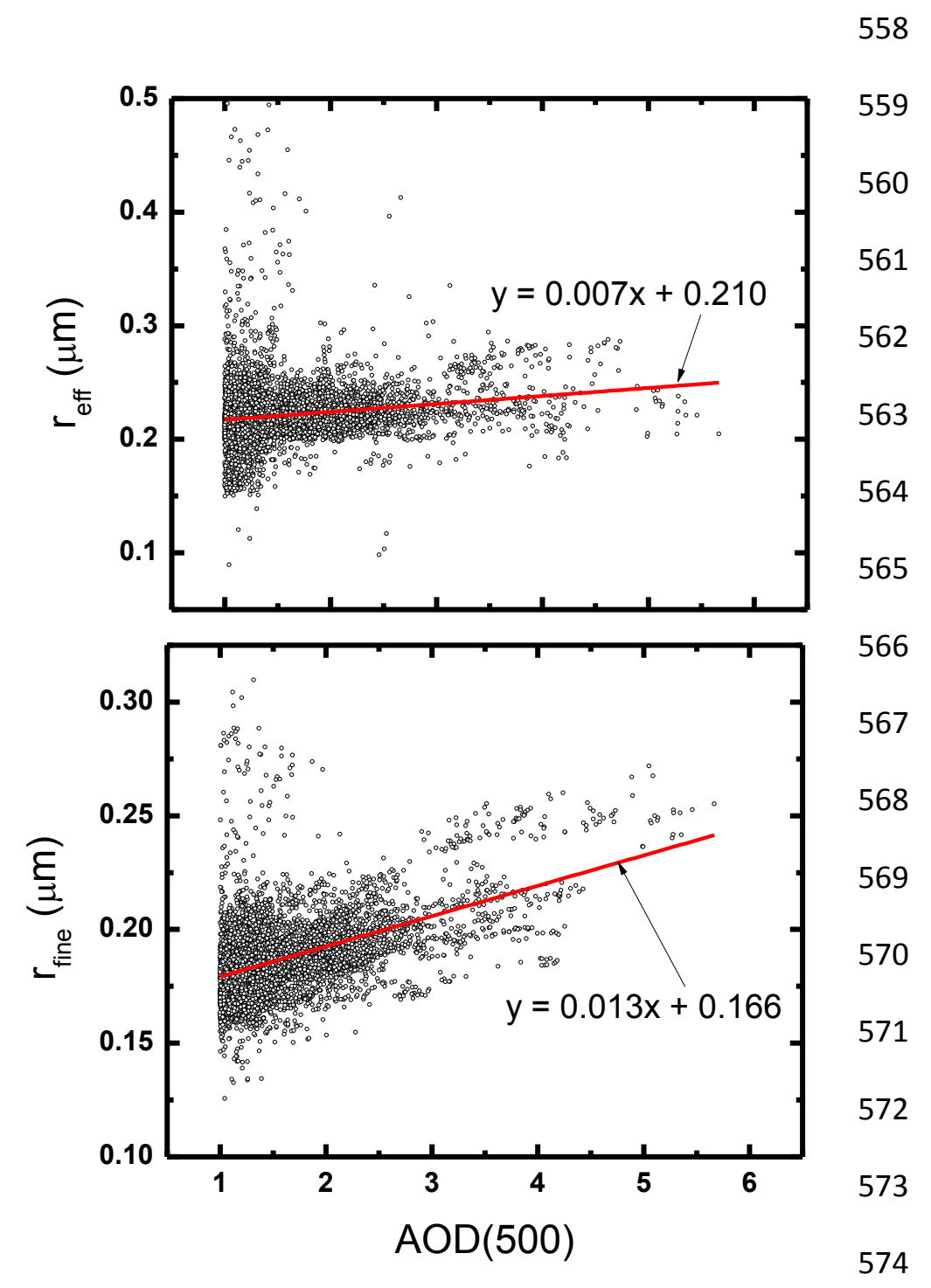

575 Figure 11: Effective radius $\left(r_{\text {eff }}\right)$ and effective radius of the fine mode $\left(r_{\text {fine }}\right)$ versus aerosol optical depth (AOD) at

$576500 \mathrm{~nm}$ for the lowland data. Data selected are for AOD > 1.0.

577

578 3.3. Aerosol Single Scattering Albedo, Refractive Index and Asymmetry Factor

For primary (directly retrieved) optical parameters such as the refractive index and derived optical parameters such as the single scattering albedo (SSA) the only source of 
581 information in this study is the AERONET almucantar scan/extinction spectrum retrieval. Level

5822.0 data, the most reliable inversion product, is constrained by several quality control criteria(see

583 Holben et al., 2006 for more details on the Level 2.0, Version 2.0 inversion criteria). Also, for

584 intensive parameters such as SSA, asymmetry factor and refractive index, the retrieval 585 uncertainties increase rapidly with decreasing AOD: this type of dependence was the motivation 586 behind the Level 2.0 criterion that limits retrievals of these parameters to conditions where $587 \operatorname{AOD}(440 \mathrm{~nm})>0.4$ (Holben et al., 2006). Because of this AOD>0.4 requirement, level 2.0 La 588 Paz data over the whole database were limited to just six retrievals acquired during the $21^{\text {st }}$ to $58925^{\text {th }}$ September 2010 period. Thus for this station only, we used Level 1.5 data that fulfilled the 590 Level 2.0 sky conditions - sky errors, solar zenith scattering angle criterion - while constraining 591 the retrievals to AOD values > 0.2. The analyses are only done for the biomass-burning seasons 592 since there are little retrievals during the other seasons. The main statistical parameters of SSA, 593 real and imaginary refractive index and asymmetry factor are listed in Table 4 (for a wavelength 594 at $500 \mathrm{~nm}$ from linear interpolation of values at 440 and $670 \mathrm{~nm}$ ).

From Table 4, SSA is generally lower in the highlands, implying more absorbing 596 particles. The imaginary part of the refractive index exhibits considerably larger values in the 597 highlands (i.e. stronger absorption with imaginary refractive index values that are, except for 598 Cuiba, greater by 0.005 than the lowland cases). The real part of the refractive index is 599 approximately the same for the different lowland stations, while the highland station values are 600 significantly higher. Finally, there are differences in the asymmetry factor, mostly in the near 601 infrared region, that are likely related to particle size differences. The changes between the 602 lowland and highland retrieval parameters of Table 4 suggest changes in particle composition 603 (notably the real part of the refractive index). 
Table 4: Mean, standard deviation (STD), median and maximum (Max.) and minimum (Min.) values of aerosol single scattering albedo (SSA), asymmetry factor $(\mathrm{g})$ and real $\left(\mathrm{m}_{\mathrm{r}}\right)$ and imaginary $\left(\mathrm{m}_{\mathrm{i}}\right)$ part of refractive index. Data are presented only for biomass-burning data as most of the data that fulfill AERONET requirements are acquired in this season. These values are the result of linearly interpolating retrieval values at 440-670 to $500 \mathrm{~nm}$. Data in brackets represent the number of retrievals for each place.

Larger SSA values being associated with the long-range transport of biomass-burning

625 particles is known in the literature (e.g. Colarco et al., 2004). In the case of inter-regional

627 composition is hypothesized to be the large differences in the availability of water vapor in the 628 atmosphere commented before: hygroscopic particles grow quickly by humidification in the 629 lowlands (see, for e.g. Kotchenruther et al., 1998 and Kreidenweis et al., 2001 for general discussions on humidity induced particle growth of smoke particles). The water vapor condenses 
631 on the particles making them larger thereby increasing their scattering efficiency while also 632 decreasing their imaginary refractive index, resulting in making them less absorbing. At higher 633 altitudes, this particle growth effect is less probable due to the less availability of water vapor as 634 well as the fact that the water coatings of particles uplifted from the lowlands may have largely 635 evaporated. In spite of the possible mixture of smoke with local particles, the lower values of the 636 real part of refractive index in the lowlands $(\sim 1.47)$ versus the highlands $(\sim 1.53)$ would support a 637 hypothesis of humidification. It must however be borne in mind that, although humidification of 638 biomass-burning particles affects their properties in general, our retrievals involve column639 integrated properties, and we must accordingly be careful to not infer more from those retrievals 640 than can be justified. Indeed, these limitations indicate that more investigations into smoke 641 dynamics are needed than we carried out in our study. In particular, experimental plans would 642 need to include resources for the measurement of vertical-profiles of aerosol properties such as 643 those performed in the SAFARI-2000 field campaign (Swap et al., 2003), either by airplanes 644 (Hobbs et al., 2003) or lidar measurements (McGill et al., 2003; Veselovskii et al., 2009). Because SSA is a key aerosol radiative forcing parameter, it is important to study both its 646 spatial and temporal evolution. To that end, Figure 12 shows the mean SSA and AOD means at $647500 \mathrm{~nm}$ (computed from linear interpolation using 440 and $675 \mathrm{~nm}$ values) for the lowland 648 stations and for each biomass-burning season during the 2000-2013 period. The year to year 649 averages of Figure 12a reflect the influence of the day-to-day variations of Figure 2 with, for 650 example, peaks in 2005, 2006, 2007 and 2010 (except that the mean values of Figure 12a seem 651 larger than expected: this is because the inversion processing protocols exclude retrievals for 652 which $\mathrm{AOD}(440)$ is less than 0.4).With respect to the SSA, we note significant station-to-station 653 variability in Figure 12b. The SSA analysis reveals curious results: for the large AOD years 


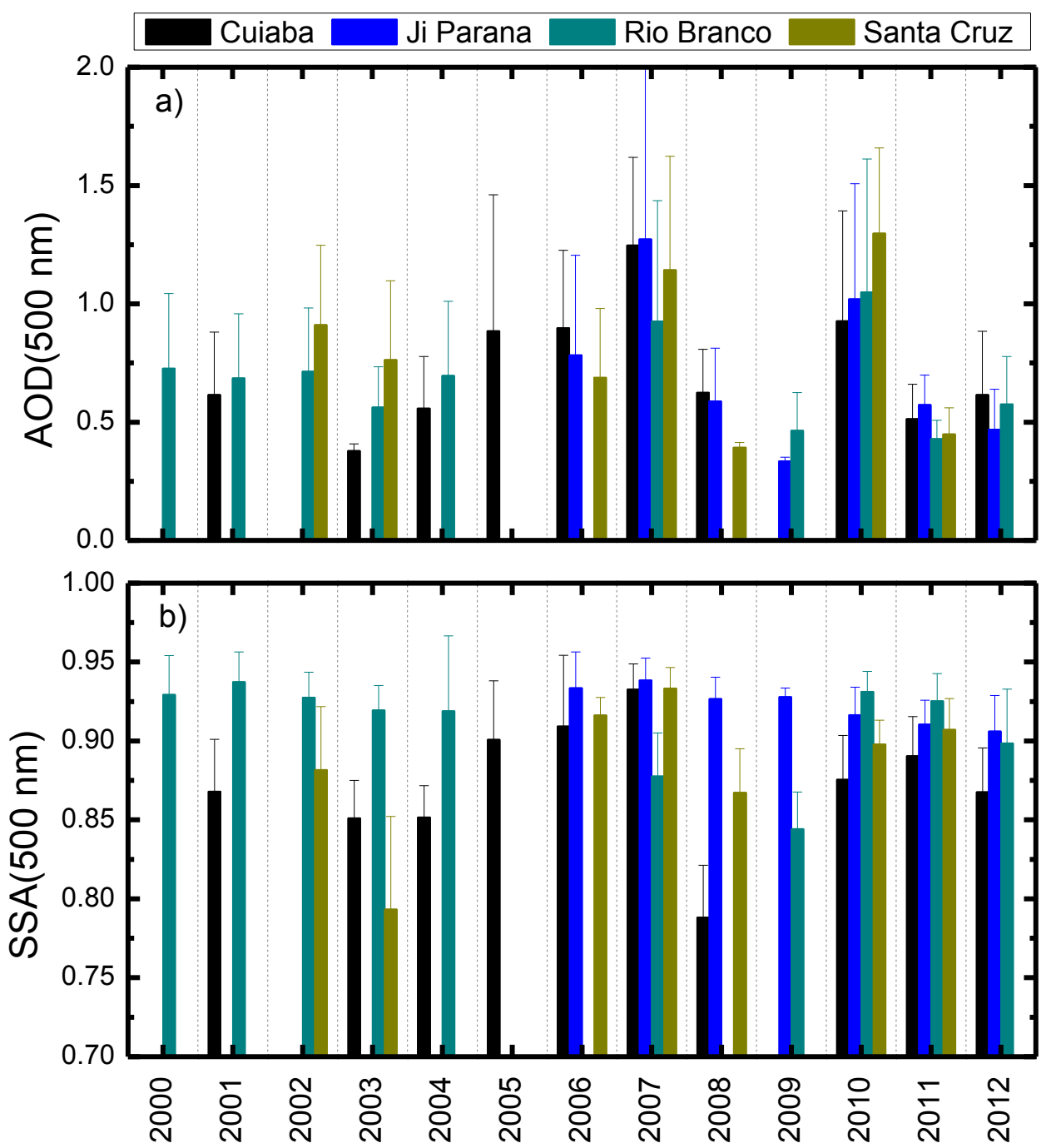

654 Figure 12: Temporal evolution of the means and standard deviations of(a) aerosol optical depth (AOD) and (b) 655 single scattering albedos (SSA) during the biomass-burning seasons for the lowland. Reference wavelength is at $656500 \mathrm{~nm}$.

$657(2005,2006,2007$ and 2010) the values of SSA are approximately similar among the stations 658 with an average that is close to 0.90. However, for the years of lower AODs (e.g. 2003, 2004 and 659 2008), SSA values are lower(0.85 - 0.78)at Cuiaba and Santa Cruz, while at Rio Branco and Ji 660 Parana the values remain around 0.92. During the years of very intense burning activity (2005, 6612006,2007 and 2010) the burned area is very extensive in area: there is accordingly an enormous 662 loading of particles in the atmosphere that arguably produce spatial homogenization of aerosol 663 properties associated with greater regional transport dynamics. For smaller AODs the aerosols 
664 are not so regionally homogenous and differences in particle properties can arise between 665 different sites.During low biomass-burning years at the southern Cuiaba and Santa Cruz sites, 666 cerrado and agricultural burning is very likely more dominant. During higher biomass-burning 667 years there would be more long-range transport of higher AOD plumes from the forest burning 668 regions towards the south and west (Freitas et al., 2005). The cerrado vegetation (savannah type) 669 burns with relatively more flaming phase combustion, thereby producing more black carbon. 670 This results in lower SSA than smoke from forest burning regions which have a higher 671 percentage of smoldering phase combustion from woody fuels therefore producing less black 672 carbon(e.g. Ward et al., 1992; Reid et al. 2005a,b).

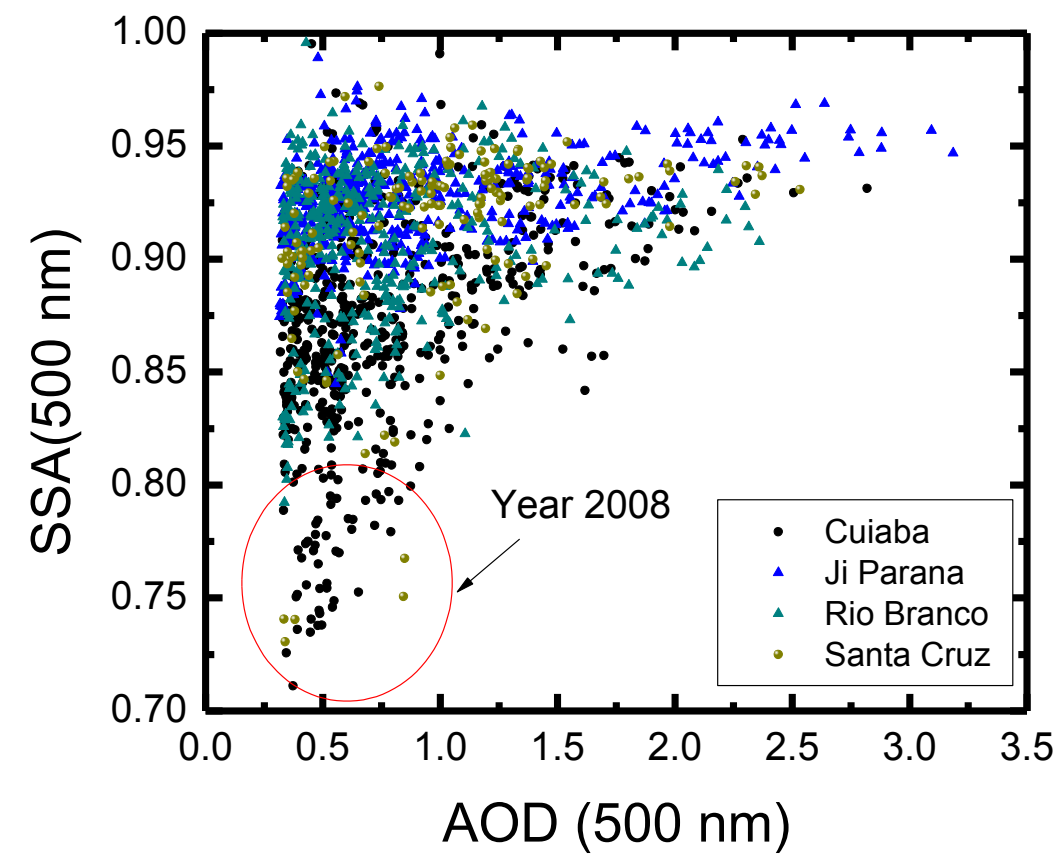

674 Figure 13: Single scattering albedo (SSA) versus aerosol optical depth (AOD) for the complete AERONET level 2.0 675 database in thelowlands.

676 A scatterplot analysis of SSA versus AOD is shown in Figure 13. The large SSA values 677 of approximately 0.90 to 0.95 for very large AOD values are observed again for all the stations. 678 For lower AODs there are, as discussed above, site-dependences with low SSA values in Cuiaba 
679 and Santa Cruz and larger values in Ji Parana and Rio Branco. Lower AOD with low SSA is 680 particularly observed in 2008, when an anomaly in the biomass-burning pattern was observed 681 using OMI data (Torres et al., 2010). For that year we note the rather extraordinary AERONET 682 station-to-station SSA differences (which the OMI sensor, with its coarse spatial resolution of $1^{\circ}$ $683 \times 1^{\circ}$, is largely insensitive to). The fact that the fires were less intense and sparser, and/or that 684 particle-type emission differences occurred between the savannah-like cerrado vegetation and the 685 rainforest, could explain the lack of SSA spatial homogeneity.

686 3.4. Aerosol transport patterns to the highlands: biomass-burning case study in September687 October 2010.

Our goal in this section is to illustrate the smoke patterns and transport from the lowlands 689 to the highlands during one carefully analysed biomass-burning season. We particularly 690 investigated the intense biomass-burning season of September-October 2010 when large AODs 691 (0.5) were registered at La Paz on a few days. Such AODs values are more than three times the 692 average at La Paz. Figure 14 shows the temporal evolution of AOD, $\alpha(440-870), r_{\text {eff }}$ and $r_{\text {fine }}$ for 693 this case study at the Cuiaba, Ji-Parama, Rio Branco, Santa Cruz and La Paz stations.

We divided the biomass-burning case study period into five sub-periods. The first 695 subperiod (I) goes from 1 to 18 September and is characterized by strong biomass-burning in the 696 lowlands with AODs of up to 3.2. The Angstrom parameters values of around 1.8 along with $\eta>$ 6970.9 indicate a predominance of fine particles. In this period there were no measurements at the 698 La Paz station until $15^{\text {th }}$ September. However, AOD values at La Paz on this day are very low 699 suggesting weak transport of biomass-particles to the Andean Altiplano. The MODIS image for 700 September $17^{\text {th }}$ (Figure 15a) shows the smoke plume had pushed toward the eastern regions 
701 (Cuiaba, Ji Parana and Santa Cruz), while the areas close to Rio Branco, the foothills and the 702 highlands, look less turbid.
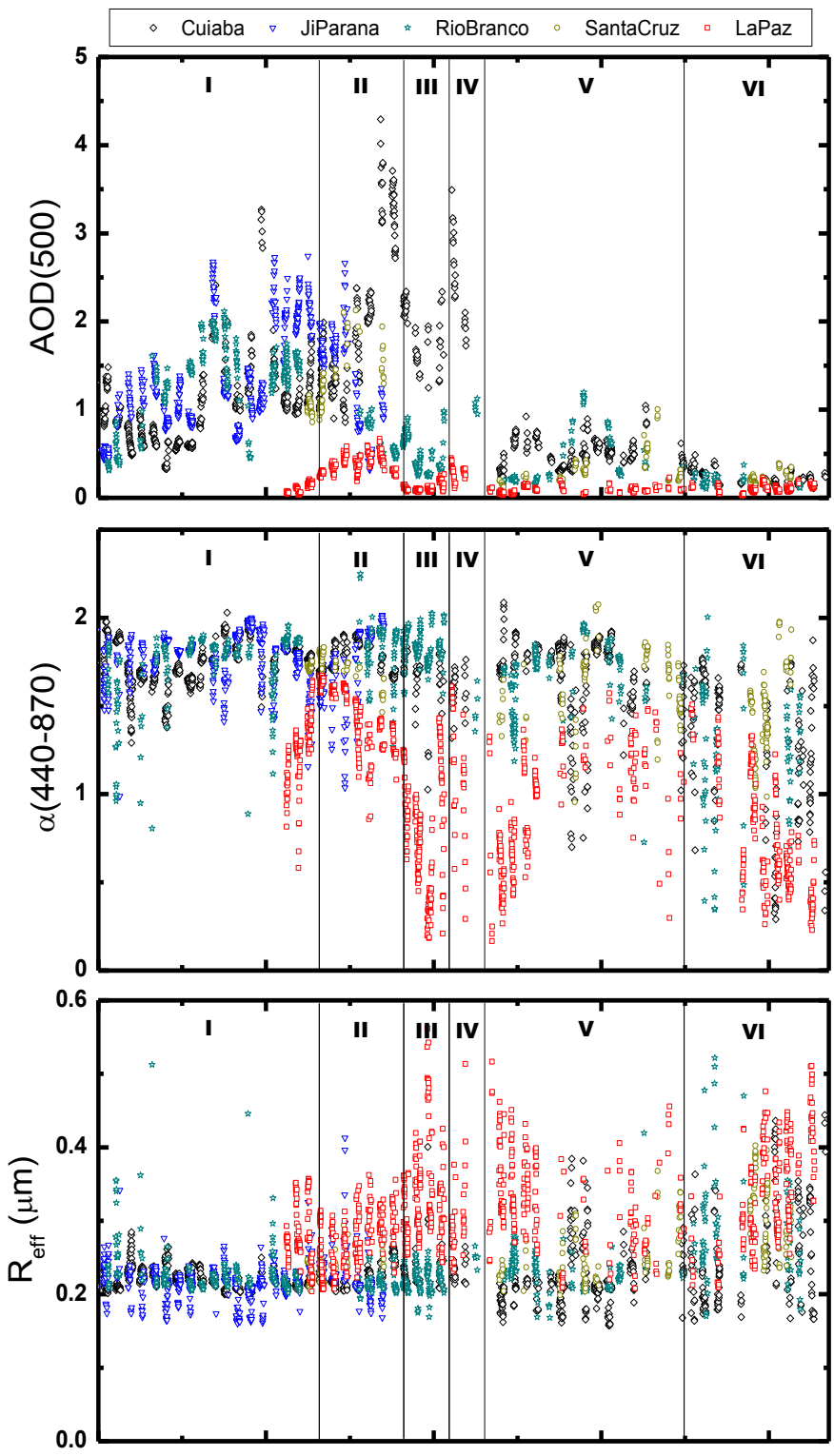

713

714

715

716

717

718

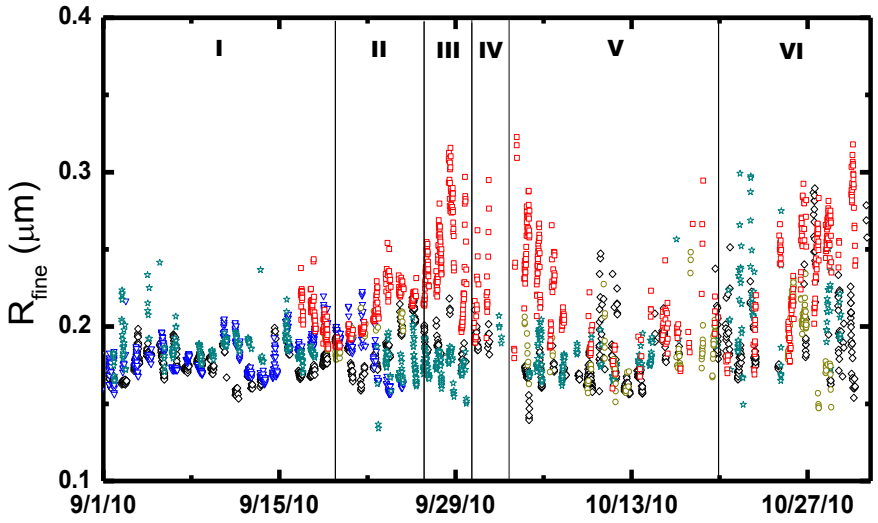

719

720 Figure 14: Temporal evolution of

721 aerosol optical at $500 \mathrm{~nm}$ (AOD),

722 Angstrom parameter $(\alpha(440-870))$,

723 effective radius $\left(r_{\text {eff }}\right)$ and effective

724 radius of the fine mode $\left(r_{\text {fine }}\right)$ for the

725 period August-October 2010. 
727 events that reach the La Paz region. Smoke plumes can be seen to be bordering the highlands in

728 the MODIS image for $21^{\text {st }}$ September (Figure 15b). In this subperiod, the largest AODs of the

729 entire database at La Paz were registered (up to 0.6), with a mean value of approximately 0.5. An

730 increase in $\alpha(440-870)$ associated with the arrival of fine mode biomass-burning particles is also

731 evident in Figure 14 . The values of $r_{\text {fine }}$ are relatively small $(\sim 0.19 \mu \mathrm{m})$, robust and stable (low

732 scatter during this day). After the third day (21 ${ }^{\text {st }}$ September), the decrease of $\alpha(440-870)$, the

733 increase of $r_{\text {eff }}$ and the clear increase of $r_{\text {fine }}$ suggest fine mode aerosol aging (maybe

734 accompanied by the presence of some coarse mode). This could be explained, for example, by

735 the growth effects (such as coagulation) induced by the accumulation of smoke particles over

736 several days (e.g. Reid et al., 2005a,b).

a) 2010-09-17 14.55

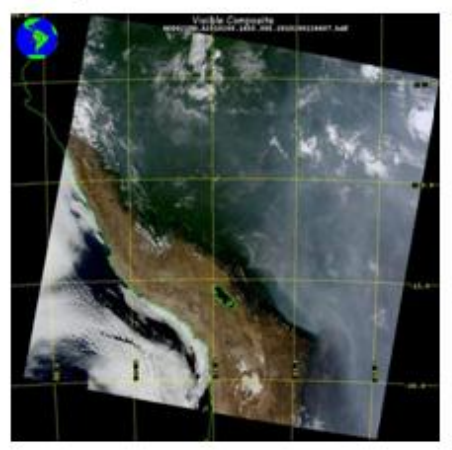

d) 2010-10-03 14.55

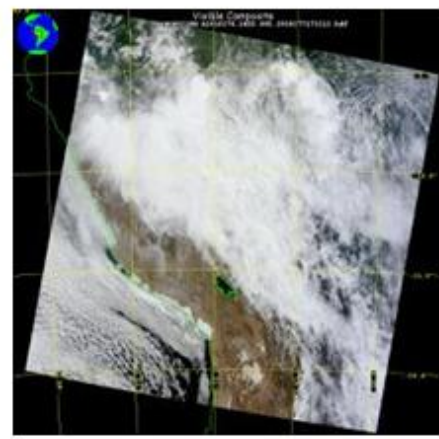

b) $2010-09-2114.30$

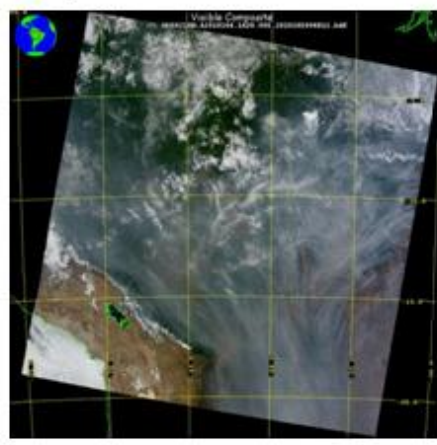

e) 2010-10-05 14.45

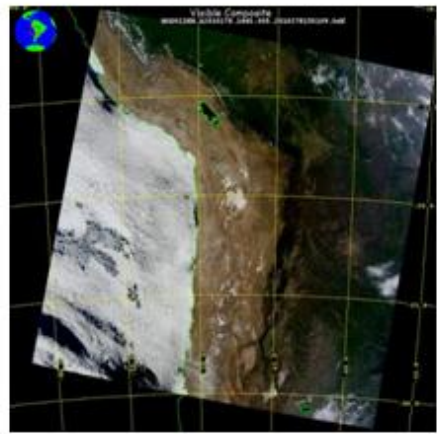

c) 2010-09-26 14.50

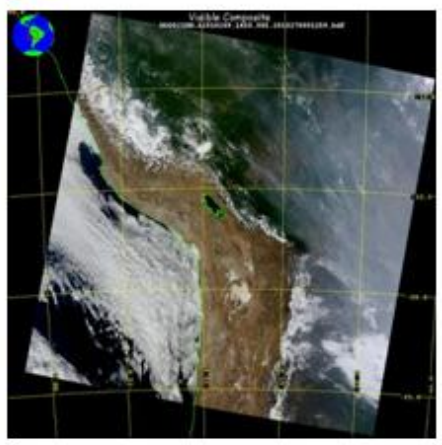

f) $2010-10-1318.20$

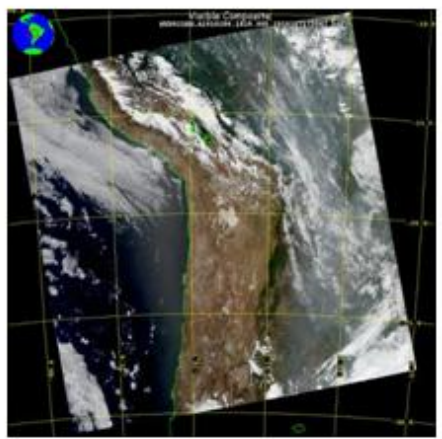


The study of air-mass transport to the highlands was initially done by computing

741 backward trajectories using HYSPLIT. On $17^{\text {th }}$ September air-masses arriving at $1500 \mathrm{~m}$ a.g.l.

742 originated over the Pacific Ocean (the backward-trajectories are provided in the supplement)

743 indicate prevailing westerly winds and explain the movement of the biomass plume towards the

744 East compared to what was observed on previous days. For the intense biomass-burning on 21st

745 September, the backward-trajectories arriving at 750 and $1500 \mathrm{~m}$ a.g.l. (graphs in the 746 supplement) encounter the mountains producing an unrealistic calculation since the vertical 747 velocities are essentially zero. The same is observed on 17 September for the $750 \mathrm{~m}$ a.g.l. 748 backward-trajectory. To ameliorate this problem, HYSPLIT offers the possibility of coupling 749 backward-trajectory calculations with a Lagrangian dispersion component (Stein et al., 2015). 750 The use of air concentration backward-trajectories allows us to represent the uncertainty in the 751 calculation arising from the model's characterization of the random motions created by 752 atmospheric turbulence. The concentration pattern identifies the potential sources that might 753 have contributed to the particles arriving at the site in question. Figure 16 shows the air 754 concentration of particles at La Paz station for integration periods of 5 days (120 hours). Model 755 initialization heights were 300 and $2000 \mathrm{~m}$ a.g.l. (approximately in and above the planetary 756 boundary layer), with a total of 25,000 particles.

Figures $16 \mathrm{a}$ and $16 \mathrm{~b}$ show very similar patterns of the potential sources that could have

758 influenced concentrations at the two representative heights of 300 and $2000 \mathrm{~m}$ a.g.1 .on $17^{\text {th }}$ 759 September 2010.The largest concentrations are $\sim 1 \mathrm{E}-13$ units $/ \mathrm{m}^{3}$ in the area surrounding La Paz. 760 Other potential sources are located in the North and Northeast regions and in the transit area 761 between the highlands and lowlands (foothills that are locally known as 'Las Yungas'). The 762 backward air concentration evaluated every 6 hours (graphs shown in the supplement) reveal that 
763 air masses that started in the previous 1-2 days had their origin in the region close to La Paz 764 while those further from the North and the Pacific Ocean are from the last 4-5 days. Such complex patterns of air concentration are associated with the westerly winds from the Pacific at high altitudes (> $1500 \mathrm{~m}$ a.g.1.) and slow winds at low altitudes (<750 $\mathrm{m}$ a.g.l.).
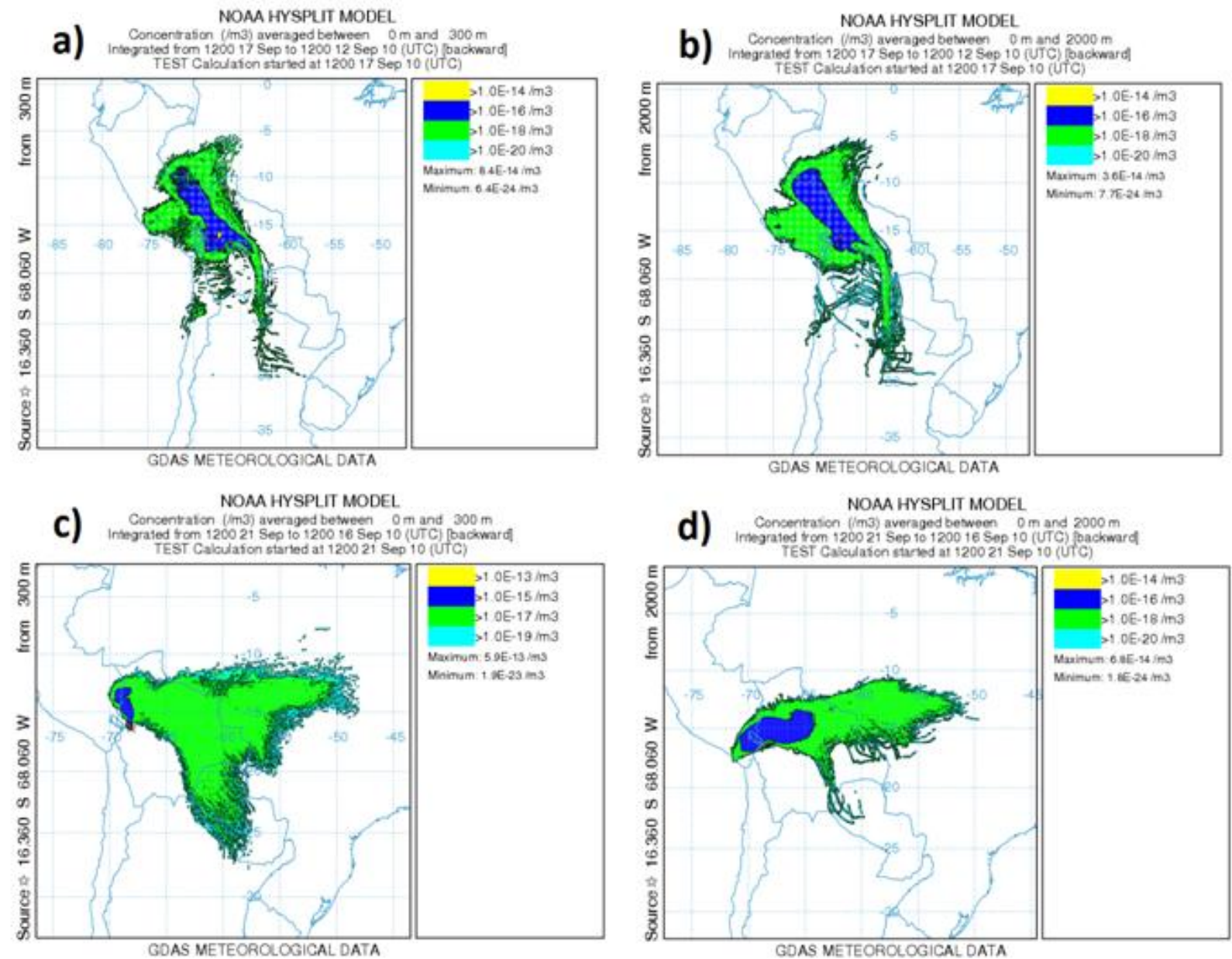

Figure 16: Air concentration backward dispersion for the city of La Paz for 17/09/2010 and 21/09/2010 for two altitude intervals: 0 to $300 \mathrm{~m}$ a.g.l. (left hand plots) and 0 to $2000 \mathrm{~m}$ a.g.l. (right hand plots). La Paz is identified by the tiny black empty star.

Figures16cand 16d also show similar patterns for the two levels on $21^{\text {th }}$ September 2010 ,

772 with almost no particles transported from the west region while the largest potential sources are

773 in the Amazonian lowlands to the east. Long-range transport is observed from the eastern regions

774 of Bolivia and its border with Brazil, and even, for the $300 \mathrm{~m}$ a.g.l. level, from more distant areas 
775 in Brazil, northern Paraguay and Argentina. The backward air concentration evaluations for 776 every 6 hours (graphs shown in the supplement) reveal that the areas with lower concentrations 777 correspond approximately to the previous 3-5 days while larger concentration areas correspond 778 to the previous $1-3$ days.

Figure 17 shows CALIPSO lidar attenuated backscatter at $532 \mathrm{~nm}$ and vertical feature mask for $20^{\text {th }}$ September 2010 when the instrument passed over South America close to the study region. The plot also shows the mean height above sea level. For the study region we observe intense attenuated backscatter that is classified by the feature mask algorithm (Omar et al., 2009) as tropospheric aerosol. According to our analyses of Figure 15 and 16 such aerosol particles correspond to smoke particles. The attenuated backscatter values are close to that found in the literature for smoke particles in Amazonia (e.g. Baars et al., 2012). It is clearly seen that the mountains act as a natural barrier, with aerosol accumulating in the lowlands along the southern and northern sides of the Andes Mountains. It is also observed that smoke plumes can reach the high mountains, but with considerably lower amounts than in the lowlands. In fact, some of these plumes have AOD values close to the detection limit of CALIPSO. All these findings agree with our general analyses of smoke particles transported to Andean high mountains. Unfortunately, CALIPSO did not cross over La Paz during the days of interest to this study and no direct comparison with this station could be done.

The third subperiod (III) from 26th to 29th September is also characterized by air-masses with origins in the Pacific Ocean (backward-trajectories not shown). Very low AODs were registered again in Rio Branco and La Paz (the western locations) and the MODIS image (Figure 15c) shows that the smoke particles have apparently moved toward the east relative to the MODIS image of Figure 15b. These findings again support the notion that strong westerly winds 
798 cleaned the atmosphere. Large highland variability in $\alpha(440-870), r_{\text {eff }}$ and $r_{\text {fine, }}$, associated with 799 large uncertainties for low aerosol loads, is observed again. The presence of coarse mode 800 particles at the highland station is again inferred from smaller values of $\alpha(440-870)$ and larger 801 values of $r_{\text {eff. }}$ The situation is however different to the East as indicated by the large AODs in 802 Cuiaba.

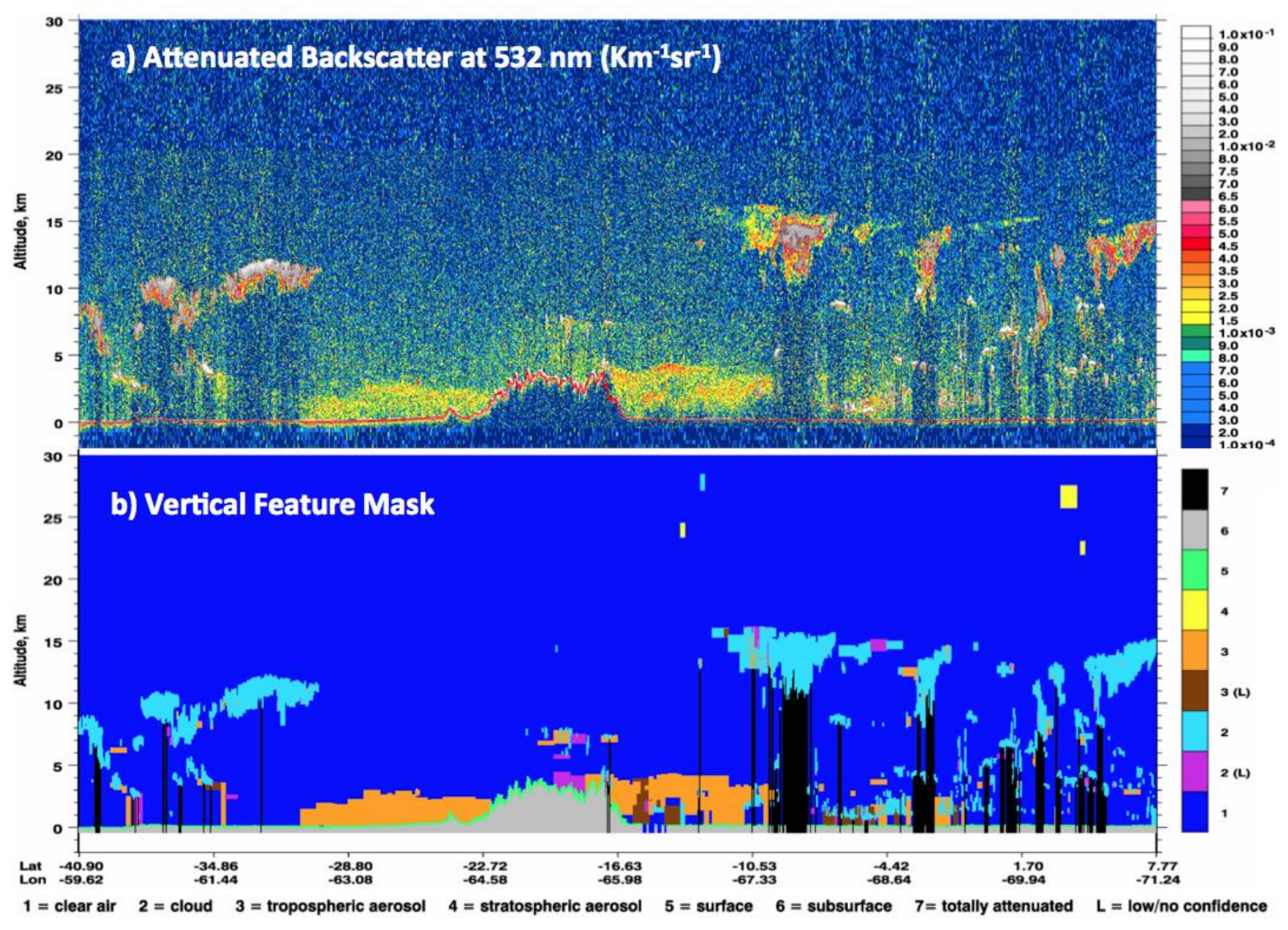

804 Figure 17: Attenuated backscatter and vertical feature mask for CALIPSO data acquired on $20^{\text {th }}$ September 2010 805 over South America. Data were acquired between 18:11:49 and 18:25:18 UTC.

The fourth subperiod (IV) extends from $30^{\text {th }}$ September to $3^{\text {rd }}$ October and is 807 characterized by a change of the air-mass origin towards the northeast in the vicinity of Peru. For 808 this case backward-trajectories (graphs included in the supplement) are not adversely affected by 809 the high mountains as they were for the other dates. During this period the most relevant factor is 
810 the significant amount of cloud cover (as observed in the MODIS image of Figure 15d) both in 811 the Pacific and in the Amazonia basin.

The last subperiods (V \& VI) of Figure 14 extends from $3^{\text {rd }}$ to $31^{\text {st }}$ October and was 813 generally characterized by the two different air-mass patterns identified above. In this subperiod 814 we note the considerably lower aerosol load at all the stations compared to the values registered 815 in September. In general the atmosphere was clean during this subperiod as illustrated by the 816 MODIS image on the $5^{\text {th }}$ of October (Figure 15e). For this day, air-masses encountered the 817 mountains and the backward dispersion air concentrations were again employed (see graphs in 818 the supplement), with patterns similar to these of Figures 16a and 16b and particles originating 819 from the northwest and southwest highlands and the Pacific Ocean. Therefore, no transport of 820 biomass-burning to La Paz was expected on October $5^{\text {th }}$, which is consistent with the weak 821 AODs of Figure 14 and the MODIS image (Figure 15e). On the other hand, between 10th and 822 15th October were registered sparse lowland biomass-burning events with some AODs above 8230.4 , high values of $\alpha(440-870)$ (close to 1.8) and stable values of $r_{\text {eff }}$ and $r_{\text {fine }}$ of 0.22 and 0.19 $824 \mu \mathrm{m}$. The MODIS Aqua image for October $13^{\text {th }}$ (Figure 15f) supports the characterization of 825 "sparse" and shows more intense and homogeneous biomass-burning plumes to the east of La 826 Paz. Air concentration backward-trajectory analyses were again required: the long-range 827 transport from the lowlands in the Amazon is similar to that observed for the intense smoke 828 events of the $20^{\text {th }}$ September at La Paz (see graphs in the supplement). In this case, however, no 829 important AOD enhancement was registered at the La Paz station. The main reason for this is 830 likely the sparse (and probably low intensity) nature of fires in the lowlands during the 10th-15th 831 October period. 
An analysis of wind regimes over La Paz for the August-October 2010 period reveals

833 that, at the 750 and $1500 \mathrm{~m}$ a.g.l. levels, 16-22\% of the cases were associated with westerly winds, while the rest (percentages around $80 \%$ ) were associated with easterly winds originated in the lowlands at the Amazonia. Although the analyses were for the particular biomass-burning season of 2010, the results may be representative of the general patterns that favour/suppress the transport of smoke particles in the tropical Andean region. More in depth studies would require the use of very high temporal-resolution meteorological data, and a large dataset of meteorological variable measurements for a more comprehensive evaluation of these patterns. Profile analyses using active remote sensing measurements are also required (e.g. multiwavelength lidar) to better understand the vertical profile of the transported smoke particles.

\section{4.- Conclusions}

We carried out an analysis of columnar aerosol properties in the South American tropical region within $10-20^{\circ}$ South and $50-70^{\circ}$ West. The area includes the Amazon (lowlands), the high mountain regions (highlands) and the transition between the two (foothills). Precipitation in the region occurs mainly in the December-March period while the June-October period is very dry. The most important geo-atmospheric factor is the strong altitude gradient between the lowlands and the highlands, which implies change in vegetation and in water vapor concentration. The contrast of aerosol properties between the lowlands and highlands is studied using the 2000-2014 AERONET measurements across the lowland stations of Rio Branco, Ji Parana, Cuiaba (stations in Brazil) and Santa Cruz (Bolivia) and the highlands station of La Paz (Bolivia). 
For the lowlands, an enhanced annual cycle in aerosol optical depth (AODs) and Angstrom parameter $(\alpha(440-870))$ was observed during the biomass-burning season (AugustOctober) across all the stations. Year to year variability, with maximum AODs in 2005, 2006, 2007 and 2010 was observed and directly linked to biomass burning activity. Using TRMM satellite data, precipitation links were studied within the context of precipitation anomalies defined as the difference between annual and climatological values for the wet (NovemberMarch) dry (April-July) and biomass-burning (August-October) seasons. Positive anomalies during the wet season influence the amount of vegetation available to be burned, while negative anomalies in the dry period favours fire activity. This hypothesis was found for the intense biomass-burning seasons in 2005, 2006, 2007 and 2010, while the opposite happens in 2009 with lower fire activity. After 2010, however, we did not observe such links with precipitation. Other factors, such as the influence of government policies on burning practices could have had an impact on our proposed relationship between rainfall anomaly and AOD and thus future investigations are needed.

The analyses during the biomass-burning season in the lowlands showed, as expected, a large predominance of fine mode particles. We also demonstrated an increase, predominantly in the fine mode, of particle radius, as AOD increases. This demonstration was achieved because we used the much more numerous retrievals of particle radius from spectral AOD measurements in spite of the larger uncertainties compared to AERONET standard retrievals. Such a finding is likely associated with the accumulation of particles. The study of the single scattering albedo (SSA) also revealed interesting findings: for the years of intense biomass-burning activity, values of SSA $(\sim 0.93)$ are homogeneous with very similar values among all the stations. However, for the years with less intense activity, such as 2008, intra-lowland differences arise with the SSA 
877 being larger $(\sim 0.95)$ at the northern stations of Rio Branco and Ji Parana and lower at the

878 southern stations of Cuiaba and Santa Cruz (SSA values with mean of $\sim 0.85$ and minimum

879 values even below 0.75). In the northern locations, the biomass burning of the rainforest

880 predominates while in the other locations cerrado and agricultural burning is more dominant. The

881 type of vegetation/rainforest burned could explain some of the differences observed in SSA.

882 More investigation is needed to confirm or reject this hypothesis.

The La Paz highlands data also showed an annual AOD cycle with maximums during the

884 biomass-burning season. These maximum values, ranging up to 0.5 , are high for this region

885 where the mean AOD is approximately 0.12. Ongoing studies with in-situ instrumentation are

886 revealing the presence of anthropogenic particles during the whole year, and the only sources in

887 the Bolvian Altiplano of such particles are the local industry and road traffic in the La Paz

888 region. Also, the natural sources of highland aerosols are associated with dust from the

889 Altiplano, which is present during the whole year. Therefore, the seasonal enhancement of AOD

890 is associated with the transport of lowland smoke. However, it was found that this transport is

891 sporadic in nature. Highland particle radii showed important differences compared to lowland

892 values: For the effective radius ( $\left.\mathrm{r}_{\mathrm{eff}}\right)$, which is sensitive to fine and coarse particles,

893 systematically larger La Paz values were likely influenced by the continuous presence of dust

894 particles from the Altiplano. The lowland station of Santa Cruz has shown the presence of coarse

895 particles which we suggested was associated with wind-driven river bed erosion. Systematically

896 larger values of fine mode radius $\left(\mathrm{r}_{\text {fine }}\right)$ were observed at La Paz over the whole year. Because

897 changes in $r_{\text {fine }}$ are attributable to changes in the fine mode, these differences were thought to be

898 due to fine mode particle aging, a mechanism that is probably favoured by the high mountain

899 wind regimes. Transport of smoke particles to the highlands was associated with larger highland 
900 values of particle size (both $r_{\text {fine }}$ and $r_{\text {eff }}$ were larger) whose growth was attributed to particle 901 aging.

The transported smoke particles to the highlands had lower values of SSA: large relative 903 (and specific) humidity in the lowlands favours particle growth by hygroscopicity with an 904 attendant decrease in optical absorption. In the highlands, however, relative (and specific) 905 humidity is quite low and it is likely that water, previously absorbed by the particles, evaporates. 906 The SSA retrieval numbers are, however, relatively small and it has not been possible to verify 907 this hypothesis. Comprehensive field campaigns will be needed to further identify the impact of 908 transported biomass-burning particles, preferably including simultaneous lowland and highland 909 measurements. These kinds of investigations are desired as future activities of the Global 910 Atmospheric Watch activities focussed on the station at Mount Chacaltaya(5240 m a.s.1.) in 911 Bolivia.

The analyses of the air-masses reaching the station of La Paz were carried out using the 913 HYSPLIT model. It has been found that the computed flow of backward-trajectories frequently 914 encounters mountains, thus introducing large uncertainties in the backward-trajectory 915 computations. Indeed, the HYSPLIT air concentration backward-dispersion has been used to 916 identify the potential sources that might have contributed to the particles arriving at the site in 917 question. The analyses of air concentration backward-dispersion have revealed that easterly 918 winds predominate allow the transport of biomass-burning particles from the Amazonian 919 lowlands, including regions of eastern Brazil, northern Paraguay and northern Argentina to the 920 highlands. On the other hand, westerly winds help to clean the atmosphere. HYSPLIT allow 921 being coupled with mesoscale models such as the Weather and Research Forecast (WRF) model, 922 and that will allow the identification of detailed transport of pollutants through the mountains. 
923 Such advances are necessary for better understanding the vulnerability of the Andean high

924 mountain regions to climate change. These climate-driven studies must be combined with others

925 in glaciology to study water resources, water quality and water use efficiency, and will support

926 environmental and economic development of the nations of the Andean regions.

\section{Acknowledgments}

928

929

930

931

932

933

934

935

936

937

938

This work was supported by the Marie Skłodowska-Curie Individual Fellowships (IF) ACE_GFAT (grant agreement No 659398), by the Postdoctoral Program of the University of Granada (Program 8), by the NASA Atmospheric Composition Program and by the NASA Aerosols, Clouds, Ecosystems mission. The work was also supported by the Andalusia Regional Government through project P12-RNM-2409 by the Spanish Ministry of Economy and Competitiveness and FEDER through project CGL2013-45410-R and CGL2016-81092-R , and by European Union's Horizon 2020 Research and Innovation Programme under grant agreement No. 654109, ACTRIS-2. The authors thankfully acknowledge the AERONET team for maintaining the stations used in this work and to the NOAA Air Research Laboratory for providing the HYSPLIT model.

\section{References}

Alados-Arboledas, L., Müller, D., Guerrero-Rascado, J.L., Navas-Guzmán, F., PérezRamírez, D., Olmo, F.J. (2011) Optical and microphysical properties of fresh biomass burning aerosol retrieved by Raman lidar, and star-and sun-photometry. Geophysical Research Letters 38.

Alastuey, A. (2017) Measurements of PM10 and PM2.5 at the Bolivian Andean Altiplano and in La Paz region. Personal Communication, Chacaltaya GAW station Scientific Steering Committee, 7 June 2017, La Paz, Bolivia. 
Andreae, M.O., Merlet, P. (2001) Emission of trace gases and aerosols from biomass burning. Global Biogeochemical Cycles 15, 955-966.

Baars, H., Ansmann, A., Althausen, D., Engelmann, R., Heese, B., Müller, D., Artaxo, P., Paixao, M., Pauliquevis, T., Souza, R. (2012) Aerosol profiling with lidar in the Amazon Basin during the wet and dry season. Journal of Geophysical Research: Atmospheres 117, $\mathrm{n} / \mathrm{a}-\mathrm{n} / \mathrm{a}$.

Bonasoni, P., Laj, P., Marinoni, A., Sprenger, M., Angelini, F., Arduini, J., Bonafè, U., Calzolari, F., Colombo, T., Decesari, S., Di Biagio, C., di Sarra, A.G., Evangelisti, F., Duchi, R., Facchini, M.C., Fuzzi, S., Gobbi, G.P., Maione, M., Panday, A., Roccato, F., Sellegri, K., Venzac, H., Verza, G.P., Villani, P., Vuillermoz, E., Cristofanelli, P. (2010) Atmospheric Brown Clouds in the Himalayas: first two years of continuous observations at the Nepal Climate Observatory-Pyramid (5079 m). Atmospheric Chemistry and Physics 10, 7515-7531.

Bond, T.C., Doherty, S.J., Fahey, D.W., Forster, P.M., Berntsen, T., DeAngelo, B.J., Flanner, M.G., Ghan, S., Kärcher, B., Koch, D., Kinne, S., Kondo, Y., Quinn, P.K., Sarofim, M.C., Schultz, M.G., Schulz, M., Venkataraman, C., Zhang, H., Zhang, S., Bellouin, N., Guttikunda, S.K., Hopke, P.K., Jacobson, M.Z., Kaiser, J.W., Klimont, Z., Lohmann, U., Schwarz, J.P., Shindell, D., Storelvmo, T., Warren, S.G., Zender, C.S. (2013) Bounding the role of black carbon in the climate system: A scientific assessment. Journal of Geophysical Research: Atmospheres 118, 5380-5552.

Boucher, E.H., and Stein, A.F. (2016). Large salt dust storms follow a 30-year rainfall cycle in the Mar Chiquita Lake (Córdoba, Argentina). PLos ONE, 11(6): e0156672, doi:10.1371journal.pone.0156672.

Bourgeois, Q., Ekman, A.M.L., Krejci, R. (2015) Aerosol transport over the Andes from the Amazon Basin to the remote Pacific Ocean: A multiyear CALIOP assessment. Journal of Geophysical Research: Atmospheres 120, 8411-8425.

Bowman, D.M.J.S., Balch, J.K., Artaxo, P., Bond, W.J., Carlson, J.M., Cochrane, M.A., D'Antonio, C.M., DeFries, R.S., Doyle, J.C., Harrison, S.P., Johnston, F.H., Keeley, J.E., Krawchuk, M.A., Kull, A.C., Marston, J.B., Moritz, M.A., Prentice, I.C., Roos, C.I., Scott, A.C., Swetnam, T.W., van der Werf, G.R., Pyne, S.J. (2009) Fire in the Earth System. Science 324, 481-484.

Bowman, D.M.J.S., Johnston, F.H. (2005) Wildfire smoke, fire management, and human health. EcoHealth 2, 76-80.

Colarco, P.R., Toon, O.B., Holben, B.N. (2003) Saharan dust transport to the Caribbean during PRIDE: 1. Influence of dust sources and removal mechanisms on the timing and magnitude of downwind aerosol optical depth events from simulations of in situ and remote sensing observations. Journal of Geophysical Research 108, 8589. 
Colarco, P.R., Schoeberl, M.R., Doddridge, B.G., Marufu, L.T., Torres, O., Welton, E.J. (2004) Transport of smoke from Canadian forest fires to the surface near Washington, D.C.: Injection height, entrainment, and optical properties. Journal of Geophysical Research 109.

Crusius, J., Schroth, A.W., Gassó, S., Moy, C.M., Levy, R.C., and Gatica, M. (2011) Glacial flourduststorms in theGulf of Alaska: Hydrologic and meteorologicalcontrols and theirimportance as a source of bioavailableiron. GeophysicalResearchLetters, 38, L06602

Dubovik, O., King, M.D. (2000) A flexible inversion algorithm for retrieval of aerosol optical properties from Sun and sky radiance measurements. Journal of Geophysical Research 105, 20673-20696.

Dubovik, O., Holben, B., Eck, T.F., Smirnov, A., Kaufman, Y.J., King, M.D., Tanre, D., Slutsker, I. (2002) Variability of absorption and optical properties of key aerosol types observed in worldwide locations Journal of the Atmospheric Sciences 59, 590-608.

Dubovik, O., Sinyuk, A., Lapyonok, T., Holben, B.N., Mishchenko, M., Yang, P., Eck, T.F., Volten, H., Muñoz, O., Veihelmann, B., van der Zande, W.J., Leon, J.-F., Sorokin, M., Slutsker, I. (2006) Application of spheroid models to account for aerosol particle nonsphericity in remote sensing of desert dust. Journal of Geophysical Research 111, D11208.

Dumka, U.C., Moorthy, K.K., Satheesh, S.K., Sagar, R., Pant, P. (2008) Short-Period Modulations in Aerosol Optical Depths over the Central Himalayas: Role of Mesoscale Processes. Journal of Applied Meteorology and Climatology 47, 1467-1475.

Eck, T.F., Holben, B.N., Reid, J.S., Dubovik, O., Smirnov, A., O'Neill, N.T., Slutsker, I., Kinne, S. (1999) Wavelength dependence of the optical depth of biomass burning, urban, and desert dust aerosols. Journal of Geophysical Research 104, 31333-31349.

Eck, T.F., Holben, B.N., Ward, D.E., Mukelabai, M.M., Dubovik, O., Smirnov, A., Schafer, J.S., Hsu, N.C., Piketh, S.J., Queface, A., Le Roux, J., Swap, R.J., Slutsker, I. (2003) Variability of biomass burning aerosol optical characteristics in southern Africa during the SAFARI 2000 dry season campaign and a comparison of single scattering albedo estimates from radiometric measurements. Journal of Geophysical Research 108.

Eck, T.F., Holben, B.N., Reid, J.S., Sinyuk, A., Hyer, E.J., O'Neill, N.T., Shaw, G.E., Vande Castle, J.R., Chapin, F.S., Dubovik, O., Smirnov, A., Vermote, E., Schafer, J.S., Giles, D., Slutsker, I., Sorokine, M., Newcomb, W.W. (2009) Optical properties of boreal region biomass burning aerosols in central Alaska and seasonal variation of aerosol optical depth at an Arctic coastal site. Journal of Geophysical Research 114.

Eck, T.F., Holben, B.N., Sinyuk, A., Pinker, R.T., Goloub, P., Chen, H., Chatenet, B., Li, Z., Singh, R.P., Tripathi, S.N., Reid, J.S., Giles, D.M., Dubovik, O., O'Neill, N.T., Smirnov, A., Wang, P., Xia, X. (2010) Climatological aspects of the optical properties of fine/coarse mode aerosol mixtures. Journal of Geophysical Research 115, D19205. 
Eck, T.F., Holben, B.N., Reid, J.S., Mukelabai, M.M., Piketh, S.J., Torres, O., Jethva, H.T., Hyer, E.J., Ward, D.E., Dubovik, O., Sinyuk, A., Schafer, J.S., Giles, D.M., Sorokin, M., Smirnov, A., Slutsker, I. (2013) A seasonal trend of single scattering albedo in southern African biomass-burning particles: Implications for satellite products and estimates of emissions for the world's largest biomass-burning source. Journal of Geophysical Research: Atmospheres 118, 6414-6432.

Eck, T., Holben, B., Giles, D., Smirnov, A., Slutsker, I., Sinyuk, A., Schafer, J., Sorokin, M., Reid, J., Sayer, A., Hsu, C., Levy, R., Lyapustin, A., Wang, Y., Rahman, M.A., Liew, S.-C., Salinas Cortijo, S.V., Li, T., Kalbermatter, D., Keong, K.L., Elifant, M., Aditya, F., Mohamad, M., Chong, T.K., San, L.H., Choon, Y.E., Deranadyan, G., Kusumanigtyas, S., Mahmud, M. (2016) Remote sensing measurements of biomass burning aerosol optical properties during the 2015 Indonesian burning season from AERONET and MODIS satellite data. In "Remote Sensing of Clouds and Aerosols: Techniques and Applications", European Geosciences Union General Assembly 2016, Vienna, Austria 17-22 April 2016. online available in http://meetingorganizer.copernicus.org/EGU2016/EGU2016-2391-3.pdf.

Freitas, S.R., Longo, K., Silva Dias, M.A.F., Silva Dias, P.L., Chatfield, R., Prins, E., Artaxo, P., Grell, G.A., Recuero, F.S. (2005) Monitoring the transport of biomass burning emissions in South America. Environmental Fluid Mechanics 5, 135-167.

Gaiero, D.M., Simonella, L., Gassó, S., Gili, S., Stein, A.F., Sosa, P., Becchio, R., Arce, J., and Marelli, H. (2013). Ground/satellite observations and atmospheric modeling of dust storms originating in the high Puna-Altiplano deserts (South America): Implications for the interpretation of paleo-climate archives. Journal of Geophysical Research: Atmospheres, 118, 3817-3831.

Gautam, R., Hsu, N.C., Tsay, S.C., Lau, K.M., Holben, B., Bell, S., Smirnov, A., Li, C., Hansell, R., Ji, Q., Payra, S., Aryal, D., Kayastha, R., Kim, K.M. (2011) Accumulation of aerosols over the Indo-Gangetic plains and southern slopes of the Himalayas: distribution, properties and radiative effects during the 2009 pre-monsoon season. Atmospheric Chemistry and Physics 11, 12841-12863.

Guirado, C., Cuevas, E., Cachorro, V.E., Toledano, C., Alonso-Pérez, S., Bustos, J.J., Basart, S., Romero, P.M., Camino, C., Mimouni, M., Zeudmi, L., Goloub, P., Baldasano, J.M., de Frutos, A.M. (2014) Aerosol characterization at the Saharan AERONET site Tamanrasset. Atmospheric Chemistry and Physics 14, 11753-11773.

Hobbs, P.V., Sinha, P., Yokelson, R.J., Christian, T.J., Blake, D.R., Gao, S., Kirchstetter, T.W., Novakov, T., Pilewskie, P. (2003) Evolution of gases and particles from a savanna fire in South Africa. Journal of Geophysical Research 108, 8485.

Holben, B.N., Eck, T.F., Slutsker, I., Tanre, D., Buis, J.P., Setzer, A., Vermote, E., Reagan, J.A., Kaufman, Y.J., Nakajima, T., Lavenu, F., Jankowiak, I., Smirnov, A. (1998) AERONET- A 
federated instrument network and data archive for aerosol characterization. Remote Sensing of Environment 66, 1-16.

Holben, B.N., Eck, T.F., Slutsker, I., Smirnov, A., Sinyuk, A., Schafer, J., Giles, D., Dubovik, O. (2006) Aeronet's Version 2.0 quality assurance criteria. Proceedings of SPIE $6408,64080 \mathrm{Q}$.

Jacobson, M.Z. (2014) Effects of biomass burning on climate, accounting for heat and moisture fluxes, black and brown carbon, and cloud absorption effects. Journal of Geophysical Research: Atmospheres 119, 8980-9002.

Kim, D., Chin, M., Yu, H., Eck, T.F., Sinyuk, A., Smirnov, A., Holben, B.N. (2011) Dust optical properties over North Africa and Arabian Peninsula derived from the AERONET dataset. Atmospheric Chemistry and Physics 11, 10733-10741.

Koren, I., Remer, L.A., Longo, K.M. (2007) Reversal of trend of biomass burning in the Amazon. Geophysical Research Letters 34, L20404.

Koren, I., Martins, J.V., Remer, L.A., Afargan, H. (2008) Smoke invigoration versus inhibition of clouds over the Amazon. Science 321, 946-949.

Koren, I., Remer, L.A., Longo, K., Brown, F., Lindsey, R. (2009) Reply to comment by W. Schroeder et al. on "Reversal of trend of biomass burning in the Amazon". Geophysical Research Letters 36, L03807.

Kotchenruther, R.A., Hobbs, P.V. (1998) Humidification factors of aerosols from biomass burning in Brazil. Journal of Geophysical Research 103, 32081-32089.

Kreidenweis, S.M., Remer, L.A., Bruintjes, R., Dubovik, O. (2001) Smoke aerosol from biomass burning in Mexico: Hygroscopic smoke optical model. Journal of Geophysical Research 106, 4831-4844.

Latrubesse, E.M., Stevaux, J.C., Cremon, E.H., May, J.-H., Tatumi, S.H., Hurtado, M.A., Bezada, M., Argollo, J.B. (2012). Late Quaternary megafans, fans and fluvio-aeolian interactions in the Bolivian Chaco, Tropical South America. Paleogeography, Paleoclimatology, Palaeoecology, 356-357, 75-88.

Longo, K.M., Freitas, S.R., Andreae, M.O., Setzer, A., Prins, E., Artaxo, P. (2010) The Coupled Aerosol and Tracer Transport model to the Brazilian developments on the Regional Atmospheric Modeling System (CATT-BRAMS) - Part 2: Model sensitivity to the biomass burning inventories. Atmospheric Chemistry and Physics 10, 5785-5795.

Lüthi, Z.L., Škerlak, B., Kim, S.W., Lauer, A., Mues, A., Rupakheti, M., Kang, S. (2015) Atmospheric brown clouds reach the Tibetan Plateau by crossing the Himalayas. Atmospheric Chemistry and Physics 15, 6007-6021. 
Maione, M., Giostra, U., Arduini, J., Furlani, F., Bonasoni, P., Cristofanelli, P., Laj, P., Vuillermoz, E. (2011) Three-year observations of halocarbons at the Nepal Climate Observatory at Pyramid (NCO-P, $5079 \mathrm{~m}$ a.s.l.) on the Himalayan range. Atmospheric Chemistry and Physics 11, 3431-3441.

Marcq, S., Laj, P., Roger, J.C., Villani, P., Sellegri, K., Bonasoni, P., Marinoni, A., Cristofanelli, P., Verza, G.P., Bergin, M. (2010) Aerosol optical properties and radiative forcing in the high Himalaya based on measurements at the Nepal Climate ObservatoryPyramid site (5079 m a.s.l.). Atmospheric Chemistry and Physics 10, 5859-5872.

Matichuk, R.I., Colarco, P.R., Smith, J.A., Toon, O.B. (2008) Modeling the transport and optical properties of smoke plumes from South American biomass burning. Journal of Geophysical Research 113.

McGill, M.J., Hlavka, D.L., Hart, W.D., Welton, E.J., Campbell, J.R. (2003) Airborne lidar measurements of aerosol optical properties during SAFARI-2000. Journal of Geophysical Research 108, 8493.

Mishra, A.K., Lehahn, Y., Rudich, Y., Koren, I. (2015) Co-variability of smoke and fire in the Amazon basin. Atmospheric Environment 109, 97-104

Morton, D.C., Defries, R.S., Randerson, J.T., Giglio, L., Schroeder, W., Van Der Werf, G.R. (2008) Agricultural intensification increases deforestation fire activity in Amazonia. Global Change Biology 14, 2262-2275.

Nogues-Paegle, J., Mo, K. (1997) Alternating wet and dry conditions over South America during summer. Monthly Weather Review 125.

Noh, Y.M., Müller, D., Shin, D.H., Lee, H., Jung, J.S., Lee, K.H., Cribb, M., Li, Z., Kim, Y.J. (2009) Optical and microphysical properties of severe haze and smoke aerosol measured by integrated remote sensing techniques in Gwangju, Korea. Atmospheric Environment 43, 879-888.

Omar, A. H., Winker, D. M., Kittaka, C., Vaughan, M. A., Liu, Z., Hu, Y., and Hostetler, C. A.. (2009) The CALIPSO automated aerosol classification and lidar ratio selectionalgorithm, Journal of Atmospheric and OceanicTechniques, 26, 1994-2014, 2009.

O'Neill, N.T., Dubovik, O., Eck, T.F. (2001a) Applied Optics. Modified Ångstrom exponent for the characterization of submicrometer aerosols 40, 2368-2375.

O'Neill, N.T., Eck, T.F., Holben, B.N., Smirnov, A., Dubovik, O., Royer, A. (2001b) Bimodal size distribution influences on the variation of Angstrom derivatives in spectral optical depth space. Journal of Geophysical Research 106.

O'Neill, N.T., Eck, T.F., Smirnov, A., Holben, B.N., Thulasiraman, S. (2003) Spectral discrimination of coarse and fine mode optical depth. Journal of Geophysical Research 108. 
O'Neill, N.T., Thulasiraman, S., Eck, T.F., Reid, J.S. (2005) Robust optical features of fine mode size distributions: Application to the Québec smoke event of 2002. Journal of Geophysical Research 110, D011207.

O' Neill, N.T., Thulasiraman, S., Eck, T.F., Reid, J.S. (2008a) Correction to "Robust optical features of fine mode size distributions: Application to the Québec smoke event of 2002". Journal of Geophysical Research 113, D24203.

O'Neill, N.T., Pancrati, O., Baibakov, K., Eloranta, E., Batchelor, R.L., Freemantle, J., McArthur, L.J.B., Strong, K., Lindenmaier, R. (2008b) Occurrence of weak, sub-micron, tropospheric aerosol events at high Arctic latitudes. Geophysical Research Letters 35.

Pérez-Ramírez, D., Aceituno, J., Ruiz, B., Olmo, F., Alados-Arboledas, L. (2008) Development and calibration of a star photometer to measure the aerosol optical depth: Smoke observations at a high mountain site. Atmospheric Environment 42, 2733-2738.

Pérez-Ramírez, D., Lyamani, H., Olmo, F.J., Whiteman, D.N., Alados-Arboledas, L. (2012) Columnar aerosol properties from sun-and-star photometry: statistical comparisons and day-to-night dynamic. Atmospheric Chemistry and Physics, 12, 97199738.

Pérez-Ramírez, D., Veselovskii, I., Whiteman, D.N., Suvorina, A., Korenskiy, M., Kolgotin, A., Holben, B., Dubovik, O., Siniuk, A., Alados-Arboledas, L. (2015) High temporal resolution estimates of columnar aerosol microphysical parameters from spectrum of aerosol optical depth by linear estimation: application to long-term AERONET and starphotometry measurements. Atmospheric Measurement Techniques 8, 3117-3133.

Queface, A.J., Piketh, S.J., Eck, T.F., Tsay, S.-C., Mavume, A.F. (2011) Climatology of aerosol optical properties in Southern Africa. Atmospheric Environment 45, 2910-2921.

Reid, J.S., Hobbs, P.V., Ferek, R.J., Blake, D.R., Martins, J.V., Dunlap, M.R., Liousse, C. (1998) Physical, chemical, and optical properties of regional hazes dominated by smoke in Brazil. Journal of Geophysical Research 103.

Reid, J.S., Eck, T.F., Christopher, S.A., Hobbs, P.V., Holben, B.N. (1999) Use of the Angstrom exponent to estimate the variability of optical and physical properties of aging smoke particles in Brazil. Journal of Geophysical Research 104.

Reid, J.S., Eck, T.F., Christopher, S.A., Koppmann, R., Dubovik, O., Eleuterio, D.P., Holben, B.N., Reid, E.A., Zhang, J. (2005a) A review of biomass burning emissions part III: intensive optical properties of biomass burning particles. Atmospheric Chemistry and Physics 5, 827-849. 
Reid, J.S., Koppmann, R., Eck, T.F., Eleuterio, D.P. (2005b) A review of biomass burning emissions part II: intensive physical properties of biomass burning particles. Atmospheric Chemistry and Physics 5, 799-825.

Remy, S., Kaiser, J.W. (2014) Daily global fire radiative power fields estimation from one or two MODIS instruments. Atmospheric Chemistry and Physics 14, 13377-13390.

Sayer, A.M., Hsu, N.C., Eck, T.F., Smirnov, A., Holben, B.N. (2014) AERONET-based models of smoke-dominated aerosol near source regions and transported over oceans, and implications for satellite retrievals of aerosol optical depth. Atmospheric Chemistry and Physics 14, 11493-11523.

Schafer, J.S., Eck, T.F., Holben, B.N., Artaxo, P., Duarte, A.F. (2008) Characterization of the optical properties of atmospheric aerosols in Amazônia from long-term AERONET monitoring (1993-1995 and 1999-2006). Journal of Geophysical Research 113.

Schwikowski, M., Brütsch, S., Gäggeler, H.W., Schotterer, U. (1999) A high-resolution air chemistry record from an Alpine ice core: Fiescherhorn glacier, Swiss Alps. Journal of Geophysical Research: Atmospheres 104, 13709-13719.

Smirnov, A., Holben, B.N., Eck, T.F., Dubovik, O., Slutsker, I. (2000) Cloud-screening and quality control algorithms for the AERONET database. Remote Sensing of Environment 73, 337-349.

Sinyuk, A., Holben, B.N., Smirnov, A., Eck, T.F., Slutsker, I., Schafer, J.S., Giles, D.M., Sorokin, M. (2012) Assessment of error in aerosol optical depth measured by AERONET due to aerosol forward scattering. Geophysical Research Letters 39, L23806.

Stein, A.F., Draxler, R.R., Rolph, G.D., Stunder, B.J.B., Cohen, M.D., Ngan, F. (2015) NOAA's HYSPLIT Atmospheric Transport and Dispersion Modeling System. Bulletin of the American Meteorological Society 96, 2059-2077.

Swap, R.J., Annegarn, H.J., Suttles, J.T., King, M.D., Platnick, S., Privette, J.L., Scholes, R.J. (2003) Africa burning: A thematic analysis of the Southern African Regional Science Initiative (SAFARI 2000). Journal of Geophysical Research: Atmospheres 108, n/a-n/a.

Torres, O., Chen, Z., Jethva, H., Ahn, C., Freitas, S.R., Barthia, P.K. (2010) OMI and MODIS observations of the anomalous 2008-2009 Southern Hemisphere biomass burning seasons. Atmospheric Chemistry and Physics 10, 3505-3513.

Uhl, C., Kauffman, J.B., Cummings, D.L. (1998) Fire in Venezuelan Amazon 2: Environmental conditions necessary for forest fires in the evergreen rainforest of Venezuela. Oikos 53, 176-184. 
Ulke, A.G., Longo, K.M., Freitas, S.R., (2011) Biomass burning in south America: transport patterns and impacts., in: Matovic, D. (Ed.), Biomass - Detection, Production and ussage.

Uriarte, M., Yackulic, C.B., Cooper, T., Flynn, D., Cortes, M., Crk, T., Cullman, G., McGinty, M., Sircely, J. (2009) Expansion of sugarcane production in São Paulo, Brazil: Implications for fire occurrence and respiratory health. Agriculture, Ecosystems \& Environment 132, 48-56.

van der Werf, G.R., Randerson, J.T., Giglio, L., Collatz, G.J., Mu, M., Kasibhatla, P.S., Morton, D.C., DeFries, R.S., Jin, Y., van Leeuwen, T.T. (2010) Global fire emissions and the contribution of deforestation, savanna, forest, agricultural, and peat fires (1997-2009). Atmospheric Chemistry and Physics 10, 11707-11735.

Van Marle, M.J.E., Field, R., van der Werf, G.R., Estrada de Wagt, I.A., Houghton, R.A., Rizzo, L.V., Artaxo, P., and Tsigaridis, K. (2016) Fire and deforestation dynamics in Amazonia (1973-2014). Global Biogeochemical Cycles, 31, doi:10.1002/2016GB005445.

Vedal, S., Dutton, S.J. (2006) Wildfire air pollution and daily mortality in a large urban area. Environ Res 102, 29-35.

Veselovskii, I., Whiteman, D.N., Kolgotin, A., Andrews, E., and Korenskii, M. (2009) Demonstration of aerosol property profiling by multiwavelength lidar under varying relative humidity conditions. Journal of Atmospheric and Oceanic Technology, 26, 15431557.

Veselovskii, I., Dubovik, O., Kolgotin, A., Korenskiy, M., Whiteman, D.N., Allakhverdiev, K., Huseyinoglu, F. (2012) Linear estimation of particle bulk parameters from multi-wavelength lidar measurements. Atmospheric Measurement Techniques 5, 1135-1145.

Veselovskii, I., Whiteman, D.N., Korenskiy, M., Kolgotin, A., Dubovik, O., PerezRamirez, D., Suvorina, A. (2013) Retrieval of spatio-temporal distributions of particle parameters from multiwavelength lidar measurements using the linear estimation technique and comparison with AERONET. Atmospheric Measurement Techniques 6, 26712682.

Veselovskii, I., Whiteman, D.N., Korenskiy, M., Suvorina, A., Kolgotin, A., Lyapustin, A., Wang, Y., Chin, M., Bian, H., Kucsera, T.L., Pérez-Ramírez, D., Holben, B. (2015) Characterization of forest fire smoke event near Washington, DC in summer 2013 with multi-wavelength lidar. Atmospheric Chemistry and Physics 15, 1647-1660.

Vuille, M. (1999) Atmospheric circulation over the Bolivian Altiplano during dry and wet periods and extreme phases of the southern oscillation. International Journal of Climatology, 19, 1579-1600. 
Ward, D.E., Susott, R.A., Kauffman, J.B., Babbitt, R.E., Cummings, D.L., Dias, B., Holben, 1308 B.N., Kaufman, Y.J., Rasmussen, R.A., and Setzer, W. (1992) Smoke and fire characteristics for cerrado and deforestation burns in Brazil: BASE-B Experiment. Journal of Geophysical Research, 97, 14601-14619.

Wonsick, M.M., Pinker, R.T., Ma, Y. (2014) Investigation of the "elevated heat pump" hypothesis of the Asian monsoon using satellite observations. Atmospheric Chemistry and Physics 14, 8749-8761.

Xu, Y., Ramanathan, V., Washington, W.M. (2016) Observed high-altitude warming and snow cover retreat over Tibet and the Himalayas enhanced by black carbon aerosols. Atmospheric Chemistry and Physics 16, 1303-1315.

Zieger, P., Kienast-Sjögren, E., Starace, M., von Bismarck, J., Bukowiecki, N., Baltensperger, U., Wienhold, F.G., Peter, T., Ruhtz, T., Collaud Coen, M., Vuilleumier, L., Maier, O., Emili, E., Popp, C., Weingartner, E. (2012) Spatial variation of aerosol optical properties around the high-alpine site Jungfraujoch (3580 m a.s.l.). Atmospheric Chemistry and Physics 12, 7231-7249. 